\title{
Pregnancy-specific malarial immunity and risk of malaria in pregnancy and adverse birth outcomes: a systematic review
}

Julia C. Cutts ${ }^{1 *}$ D, Paul A. Agius ${ }^{1,2}$, Zaw Lin ${ }^{1,3}$, Rosanna Powell ${ }^{1}$, Kerryn Moore ${ }^{1,3}$, Bridget Draper $^{1}$, Julie A. Simpson ${ }^{3}$ and Freya J. I. Fowkes ${ }^{1,2,3,4^{*}}$

\begin{abstract}
Background: In endemic areas, pregnant women are highly susceptible to Plasmodium falciparum malaria characterized by the accumulation of parasitized red blood cells (pRBC) in the placenta. In subsequent pregnancies, women develop protective immunity to pregnancy-associated malaria and this has been hypothesized to be due to the acquisition of antibodies to the parasite variant surface antigen VAR2CSA. In this systematic review we provide the first synthesis of the association between antibodies to pregnancy-specific $P$. falciparum antigens and pregnancy and birth outcomes.
\end{abstract}

Methods: We conducted a systematic review and meta-analysis of population-based studies (published up to 07 June 2019) of pregnant women living in P. falciparum endemic areas that examined antibody responses to pregnancy-specific $P$. falciparum antigens and outcomes including placental malaria, low birthweight, preterm birth, peripheral parasitaemia, maternal anaemia, and severe malaria.

Results: We searched 6 databases and identified 33 studies (30 from Africa) that met predetermined inclusion and quality criteria: 16 studies contributed estimates in a format enabling inclusion in meta-analysis and 17 were included in narrative form only. Estimates were mostly from cross-sectional data (10 studies) and were heterogeneous in terms of magnitude and direction of effect. Included studies varied in terms of antigens tested, methodology used to measure antibody responses, and epidemiological setting. Antibody responses to pregnancyspecific PRBC and VAR2CSA antigens, measured at delivery, were associated with placental malaria (9 studies) and may therefore represent markers of infection, rather than correlates of protection. Antibody responses to pregnancy-specific pRBC, but not recombinant VAR2CSA antigens, were associated with trends towards protection from low birthweight (5 studies).

Conclusions: Whilst antibody responses to several antigens were positively associated with the presence of placental and peripheral infections, this review did not identify evidence that any specific antibody response is associated with protection from pregnancy-associated malaria across multiple populations. Further prospective cohort studies using standardized laboratory methods to examine responses to a broad range of antigens in different epidemiological settings and throughout the gestational period, will be necessary to identify and prioritize pregnancy-specific $P$. falciparum antigens to advance the development of vaccines and serosurveillance tools targeting pregnant women.

Keywords: Malaria, Plasmodium falciparum, Pregnancy, Immunity, Antibodies, Epidemiology, Systematic review, Meta-analysis

\footnotetext{
* Correspondence: julia.cutts@burnet.edu.au; freya.fowkes@burnet.edu.au

${ }^{1}$ Burnet Institute, 85 Commercial Road, Melbourne, Victoria 3004, Australia

Full list of author information is available at the end of the article
}

(c) The Author(s). 2020 Open Access This article is distributed under the terms of the Creative Commons Attribution 4.0 International License (http://creativecommons.org/licenses/by/4.0/), which permits unrestricted use, distribution, and reproduction in any medium, provided you give appropriate credit to the original author(s) and the source, provide a link to the Creative Commons license, and indicate if changes were made. The Creative Commons Public Domain Dedication waiver (http://creativecommons.org/publicdomain/zero/1.0/) applies to the data made available in this article, unless otherwise stated. 


\section{Background}

In malaria-endemic areas, individuals can acquire clinical immunity to Plasmodium falciparum malaria after repeated exposure and symptomatic episodes in adults are relatively rare [1]. Despite this acquired immunity, pregnant women are highly susceptible to $P$. falciparum malaria. Pregnancy-associated malaria (PAM) represents a major public health problem, leading to poor outcomes for both mother and infant, including maternal mortality, maternal anaemia, miscarriage, stillbirth, low birthweight, and preterm birth [2-7]. In endemic regions, primigravidae are at greatest risk of PAM, and the frequency and density of both placental and peripheral $P$. falciparum infection decreases with successive pregnancies [3, 8-12].

Malaria in pregnancy is characterized by the accumulation of $P$. falciparum parasitized red blood cells $(\mathrm{pRBC})$ in the placental intervillous space, often observed with macrophage infiltration, fibrinoid, and parasite pigment deposits [13, 14]. Parasites taken from infected placentas display preferential binding to the glycosaminoglycan chondroitin sulfate A (CSA) [15], present on the surface of placental syncytiotrophoblasts and intervillous spaces [15-17]. This binding phenotype is rarely observed in parasites taken from non-pregnant individuals $[15,18-21]$, which are more likely to bind to receptors CD36 and ICAM-1 in the vascular endothelium. Thus, the parasites that infect pregnant women are understood to constitute a distinct population to those that infect non-pregnant individuals. Parasite binding to CSA on syndecan-1 [22] is mediated by the P. falciparum erythrocyte membrane protein 1 (PfEMP1) family member VAR2CSA [23-27], expressed on the surface of pRBC. VAR2CSA is a large $(350 \mathrm{kDa})$ protein with six Duffy-binding-like (DBL) domains (DBL1-6) and three interdomain (ID) regions [28-30]. The development of protective immunity to PAM over successive pregnancies has largely been assumed to be due to the acquisition of antibodies to VAR2CSA, specifically those that block adhesion to CSA. Two vaccine candidates based on the N-terminal CSA-binding region of VAR2CSA [28] have entered early-stage clinical trials: PAMVAC is comprised of domains ID1-DBL2X-ID2a from the P. falciparum strain FCR3 [31, 32] and PRIMVAC is comprised of domains DBL1X-DBL2X from P.f. 3D7 [33].

Several studies have demonstrated parity-dependent increases in antibody responses to pregnancy-specific variant surface antigens on pRBC [18, 21, 34-36], antiadhesion antibodies to CSA-binding parasites [37, 38], and some, but not all, VAR2CSA domains [39-42], and a stronger correlation between parity and antibody responses has been observed in areas of more intense transmission [43]. Despite strong evidence for paritydependent acquisition of antibodies to VAR2CSA, and evidence for a role for VAR2CSA in mediating adhesion to CSA in the placenta, direct epidemiological evidence for a protective effect of VAR2CSA antibodies in preventing PAM and associated adverse pregnancy and birth outcomes has been inconsistent. Furthermore, the specific antigenic targets, and functional responses necessary for protection against malaria in pregnancy and poor birth outcomes has not been established across multiple populations. We conducted a systematic review and meta-analysis of population-based studies examining associations between antibodies to pregnancy-specific $P$. falciparum antigens, and pregnancy and birth outcomes including placental malaria, low birthweight, preterm birth, maternal anaemia, and severe malaria. A more comprehensive understanding of the acquired immune response to PAM will inform vaccine development and may help to identify serological correlates of immunity that could be employed in serosurveillance tools.

\section{Methods \\ Review protocol}

The Meta-analysis of Observational Studies in Epidemiology (MOOSE) working group [44] guidelines and the Preferred Reporting Items for Systematic Reviews and Meta-Analyses (PRISMA) specifications were adhered to in the conducting and reporting of this systematic review and meta-analysis [45]. A completed PRISMA checklist is included in Additional file 1.

\section{Search methods for identification of studies}

PubMed, Web of Science, Scopus, African Index Medicus, LILACS (Latin American and Caribbean Health Sciences Literature), and the Malaria in Pregnancy Consortium databases were searched for studies published in all years up to and including 07 June 2019 that examined the association of antibody responses to pregnancy-specific $P$. falciparum antigens and pregnancy and birth outcomes. Key words included VAR2CSA, falciparum, pregnancy, parasitaemia, IgG, DBL, placental infection, antibody, immunity, protection, VSA, variant surface antigen, PfEMP1, birth outcome, birthweight, gestational age, preterm birth, and intrauterine growth restriction. Google Scholar was used to identify additional studies by senior authors of some studies identified through other database searches but was not used in a systematic manner due to the unwieldy number of records returned using key words listed above. The reference lists of obtained papers were searched for further studies. Studies reported in languages other than English were included and translated into English using online translation applications. We did not formally attempt to identify unpublished population studies because it would require us to provide substantial descriptions of the study design, sample testing and analysis used in the 
studies, and a review of ethical and other issues. The full search strategy for one database (PubMed) is provided (Additional file 2).

\section{Criteria for considering studies for this review Study designs and study participants}

Population-based cross-sectional, case-control, cohort studies, including treatment to reinfection studies, and randomized controlled trials (RCTs), excluding vaccine efficacy trials, were included. The primary criterion for study inclusion was pregnant women living in areas endemic for P. falciparum infection. All geographical locations were included. Studies which included multiple population subsets were assessed on a sub-population basis to determine eligibility for inclusion.

\section{Antibody measures}

We included studies that measured immunoglobulin G (IgG) responses to placental isolates, pregnancy-specific parasite strains including CS2, and other strains that had been selected for binding to chondroitin sulfate/chondroitin sulfate proteoglycans, and recombinant or synthetic defined pregnancy-specific variant surface antigens. Studies that employed the following types of assays to measure total antibody responses were considered: enzyme-linked immunosorbent assay (ELISA), multiplex assay, and flow cytometry. We also included studies that measured functional antibody responses to pregnancy-specific $\mathrm{pRBC}$, including CSA binding inhibition (anti-adhesion assay), pRBC cell-agglutination, and phagocytosis. Studies in which antibodies were measured in peripheral blood taken during pregnancy and/or the immediate postpartum period were considered. For cohort studies and RCTs, if antibody responses were measured at more than two time points, results from enrolment and the latest (e.g. delivery) sampling time were extracted. Estimates from cohort studies and RCTs in which antibody responses were determined after the outcome measures of interest were excluded.

\section{Maternal and birth outcomes}

Outcome data were measured during pregnancy, at birth, or during the immediate postpartum period (within $72 \mathrm{~h}$ of delivery). If not presented in the requisite format in the original papers, authors were asked to provide data for maternal $P$. falciparum placental malaria, maternal peripheral $P$. falciparum infection, low birth weight $(<2500 \mathrm{~g})$, premature birth (delivery before 37 weeks of gestation), and anaemia or severe anaemia (as defined in each study), and severe malaria, where relevant. We included estimates where women with active or active-chronic placental infection were compared to women with no placental infection, but we did not include past placental infection (often characterized by the presence of haemozoin in fibrin) as an outcome because in such cases the temporal relationship between antibody responses and infection would be difficult to ascertain, nor did we include estimates where active placental infection was compared with past infection.

\section{Quality criteria}

The minimum quality criteria for inclusion of studies were as follows: for placental malaria, confirmation of $P$. falciparum placental infection by slide microscopy of placental blood, polymerase chain reaction (PCR), or placental histology for the examination of $P$. falciparum parasites; for peripheral parasitaemia, detection by slide microscopy or PCR; for low birth weight, defined as less than $2500 \mathrm{~g}$ and birth weight was measured within $72 \mathrm{~h}$ of birth; and for preterm birth, defined as delivery at less than 37 weeks gestation, where gestational age must have been confirmed using Crown Rump Length (CRL) from Ultrasound and Robinson's chart or date of last menstrual period (LMP). Studies that used rapid diagnostic tests as the sole method of diagnosis for $P$. falciparum infection were excluded. Antibody levels must have been determined in maternal peripheral blood samples preceding or at the same time as outcome measurement. Studies in which antibodies were measured in cord blood, placental blood, or infant peripheral blood were excluded. Cut-offs for positive antibody responses by ELISA or other means must have been defined using unexposed (malaria-naïve) controls or men/children from the malaria-endemic area.

\section{Selection of studies}

Three authors (JCC, RP, and ZL) identified possible studies and assessed the methodological quality of included studies independently, with discrepancies resolved by discussion with a fourth review author (FJIF).

\section{Approaches to include all available studies and data}

For studies that analysed antibody levels as the outcome variable rather than the exposure variable, where possible, data were extracted and re-analysed with the specified maternal/birth outcome as the outcome variable. If the raw data were not presented, authors of the study were invited to re-analyse or provide data for the inclusion of their study in the systematic review. In addition, we contacted several authors whose studies did not meet the inclusion criteria but contained data that were eligible for the systematic review. Contact was established through an initial email explaining the nature of the systematic review and the information required, together with a data extraction form for authors to complete (Additional file 3). If the corresponding author did not respond within three email attempts, then no further action was taken. 


\section{Risk of bias}

For cross-sectional, RCTs, and cohort studies, selection bias was assessed by reviewing inclusion and exclusion criteria of each study. For case-control studies, the comparability of cases and controls was assessed. An additional selection bias can occur in case-control studies when cases and/or controls are selected based on criteria relating to their exposure (i.e. antibody) status or there are differences in the reporting of exposure between cases and controls. However, this is unlikely because immunoassays were after enrolment into the study. Information bias (resulting from flaws in measuring antibody and $P$. falciparum outcome data) is unlikely because antibodies are measured using immunoassays that are standardized within each study and across outcome groups. Furthermore, the quality criterion of this review ensures accurate measurement of maternal and infant outcomes and it is unlikely that measurement of outcomes would differ according to antibody groups. Initially, two authors (JCC and RP) independently assessed bias, with discrepancies resolved by discussion with a third review author (FJIF). Risk of bias assessment was collated by JC using the Risk of Bias in Non-randomized Studies-of Interventions (ROBINS-I) tool (Additional file 4) [46]. The risk of bias assessment pertains to the association between antibody responses and pregnancy and birth outcomes derived from the study, rather than the study itself.

\section{Data analysis}

\section{Data collection}

Measures of association between antibody responses and maternal and birth outcomes (odds ratios [ORs], risk ratios [RRs], incidence rate ratios [IRRs], or hazard ratios [HRs]) and corresponding 95\% confidence intervals (CIs) were extracted or derived using reported data or unpublished data provided by authors. OR, RR, HR, and IRR are hereinafter denoted as RR. Data extraction was performed independently by two review authors (JCC and $\mathrm{RP}$ ) using the data extraction form (Additional file 3). For cross-sectional and case-control studies, odds ratios (ORs) were extracted or calculated where possible. For cohort studies and RCTs, risk ratios (RR), hazard ratios (HR), and incidence rate ratios (IRR) were extracted or calculated where possible or unadjusted ORs were converted to RR [47]. If provided, cross-sectional data from RCTs and cohort studies were extracted for inclusion in cross-sectional analyses. Basic information about each study, including enrolment years, age of women, and IPTp use, was extracted from individual publications where available. P. falciparum endemicity was categorized as low, intermediate, or high using information in the published papers. If insufficient information was provided in the publication, we used the Malaria Atlas
Project website (https://map.ox.ac.uk) to obtain estimates of the Plasmodium falciparum parasite rate in 210 year olds (globally, 2000-2017) for each study site (longitude and latitude). We then categorized the endemicity of the study sites as follows: low $[<10 \%]$, intermediate $[\geq 10 \%$ to $<50 \%]$, or high $[\geq 50 \%]$.

\section{Standardization of antibody measures}

Measurement of antibody levels by established assays (ELISA or flow cytometry) does not produce a common metric among studies. Antibody data classified as "responders" or "non-responders" relative to a negative control (unexposed sera) were pooled, whereas categories based upon arbitrary cut-offs (including categories of responders based on statistical rankings) were simply reported in tables, but not included in the forest plots or meta-analyses. For studies where the antibody measures were analysed as continuous exposure variables, authors were asked to re-analyse their data by collapsing the antibody data into categories. If antibody or outcome data could not be provided in categorical form, the study's key findings on the association between antibody responses and outcomes of interest were described in Table 2 and in the text, that is, the study was included in narrative terms rather than quantitative terms. For studies in which responses to multiple allelic forms of an antigen or multiple parasite isolates or strains were analysed, estimates for the most seroprevalent antibody response were presented for that population. Data on total IgG responses or the most seroprevalent subclass response were also extracted. If antibody responses to the same antigen, in the same population-based study, were reported in several publications, results from the largest sample size were presented. Separate estimates were obtained for the RR associated with pRBC VSA, VAR2CSA: DBL1， DBL1+2，ID1-ID2，ID1-ID2a，DBL2，DBL3X, DBL3-4, DBL4, DBL5, and full-length VAR2CSA (FV2). Separate estimates were calculated for functional antibody responses. Sub-group analyses were performed on women stratified by gravidity (primigravidae and multigravidae), where this was possible.

\section{Synthesis of results: meta-analysis}

A meta-analysis was performed, stratified by outcome, and where relevant VAR2CSA antigen and trimester of antibody and outcome determination. Cross-sectional estimates from all study designs, except for case-control studies, were combined where possible; prospective estimates from RCTs and cohort studies were combined where possible. Where there were sufficient data, a pooled estimate for each malaria outcome was calculated using a random effects model. The standard error of the natural logarithm (ln) of the RR was calculated using the formula SE(ln RR) $=(\ln ($ upper limit of $95 \% \mathrm{CI})-\ln (\mathrm{RR})) / 1.96$. The random 
effects meta-analyses were weighted using the inverse of the sum of the individual study sampling variances and a between-study variance component [48]. The application of weights to individual study estimates in pooled effect estimation ensure (typically smaller) studies exhibiting higher standard error do not bias point estimates and contribute to under estimation of pooled effect confidence intervals. Heterogeneity between studies was tested with the $I^{2}$ statistic [49]. If the $I^{2}$ statistic was $\leq 75 \%$, a metaanalysis based on a random effects model was conducted; when the $I^{2}$ statistic was $>75 \%$ and/or the lower $95 \%$ confidence limit was between 50 and $100 \%$, the studies were not combined $[49,50]$. All analyses were performed using STATA version 15.1 .

\section{Results}

Identification and description of included studies

Database searches identified 795 records, from which 122 potentially relevant studies were selected based upon title and abstract. The full texts of these studies were examined to determine whether they complied with eligibility criteria: 73 did not meet the inclusion criteria; 3 fulfilled the inclusion and quality criteria; 46 studies potentially met inclusion and quality criteria and authors were contacted with responses received from authors of 44 studies (Fig. 1). Of the 44 responders, 13 authors provided data or estimates to fulfill inclusion and quality criteria, and for the remaining 31 studies, the data were not available or did not meet inclusion/quality criteria. Details of excluded studies are provided in Additional file 5 . A total of 33 studies were included in the systematic review: 16 studies contributed estimates in a format enabling inclusion in meta-analysis [35, 42, 43, 51-63] (Table 1) and 17 studies are included in narrative terms only because data were not available in the required format [27, 34, 38, 39, 64-76] (Table 2). Of those 16 studies that contributed estimates, 4 were crosssectional, 4 were cohort (two of which contributed only cross-sectional data), 6 were case-control studies, and 2 were randomized controlled trials. The included

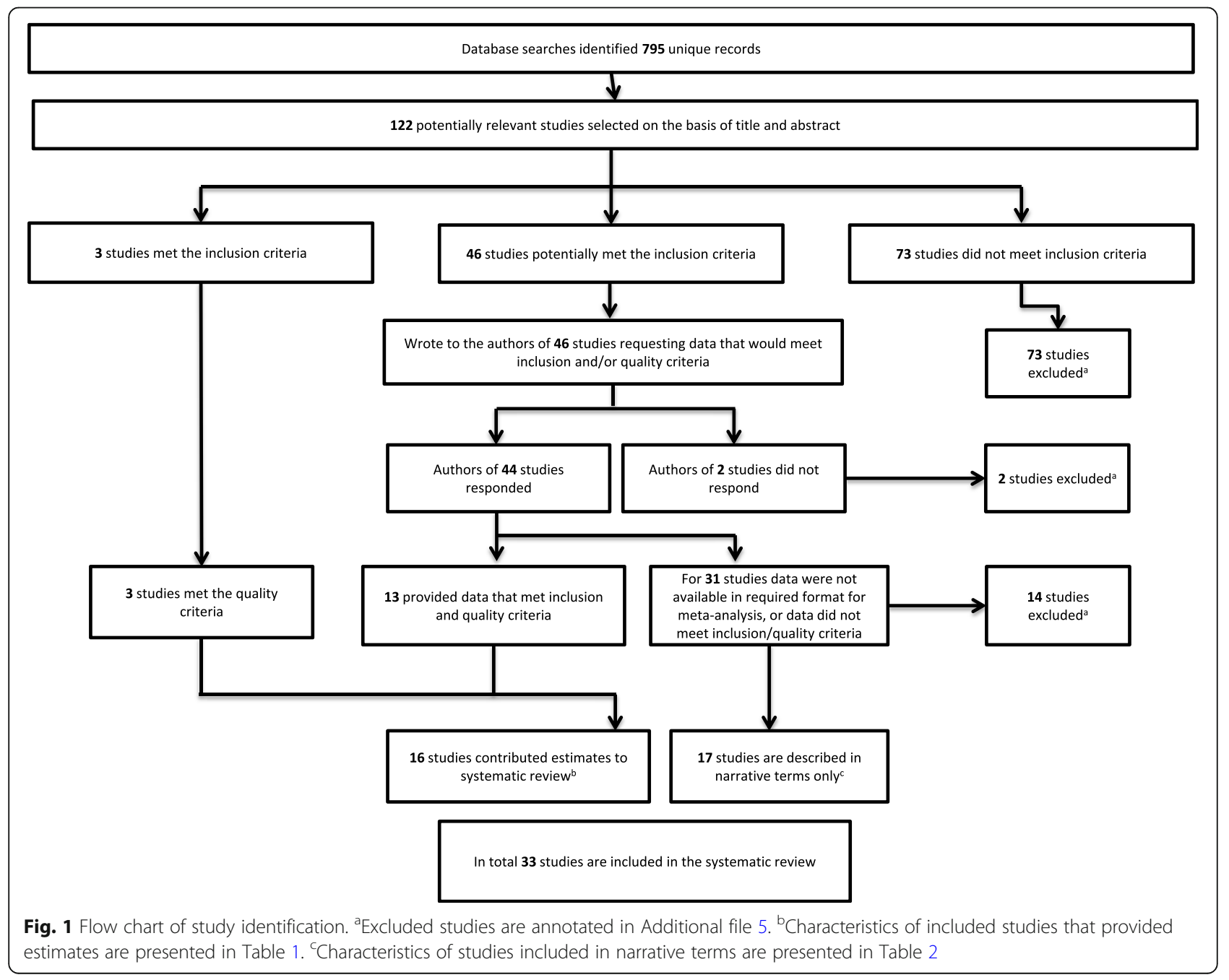




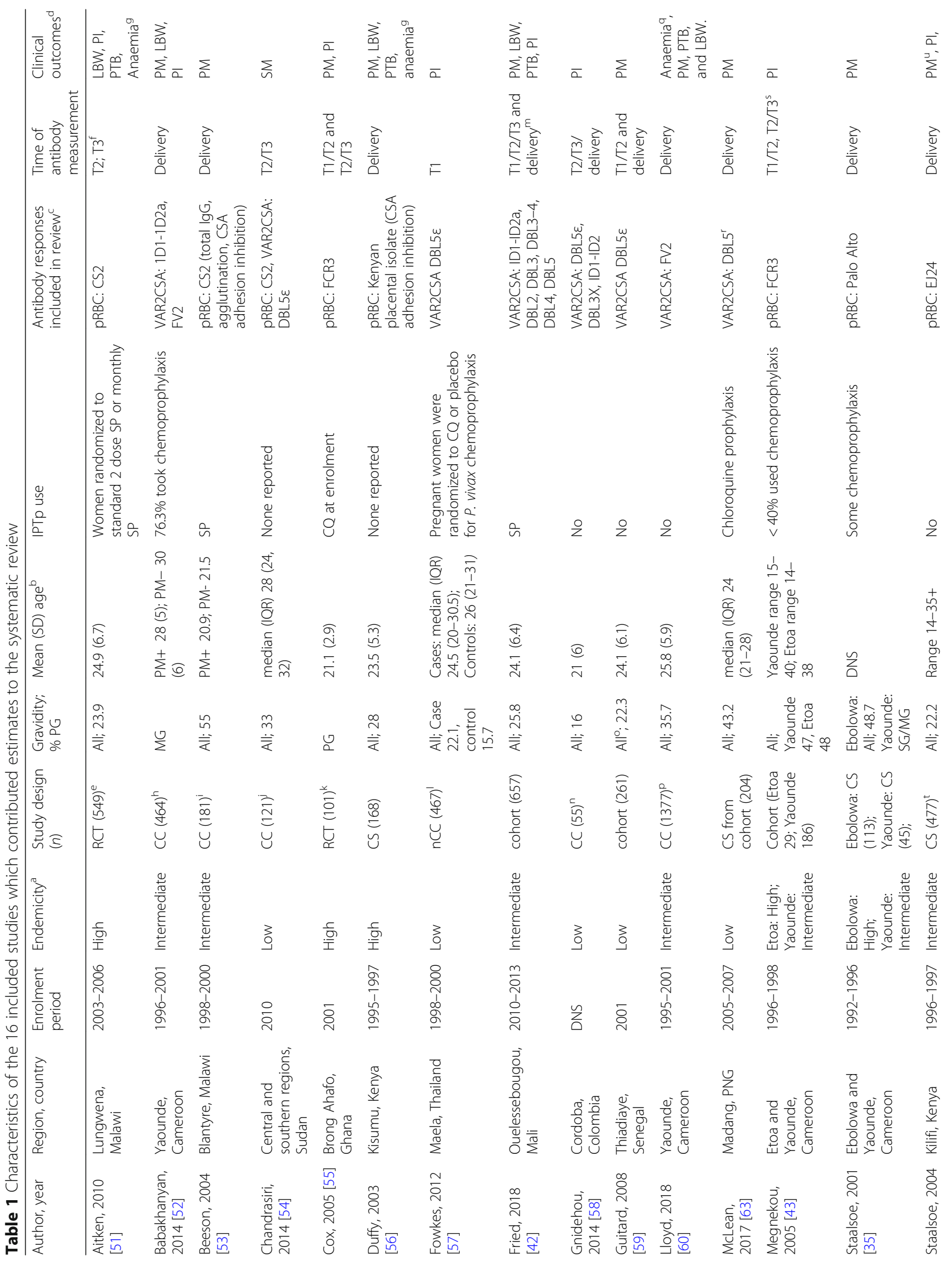




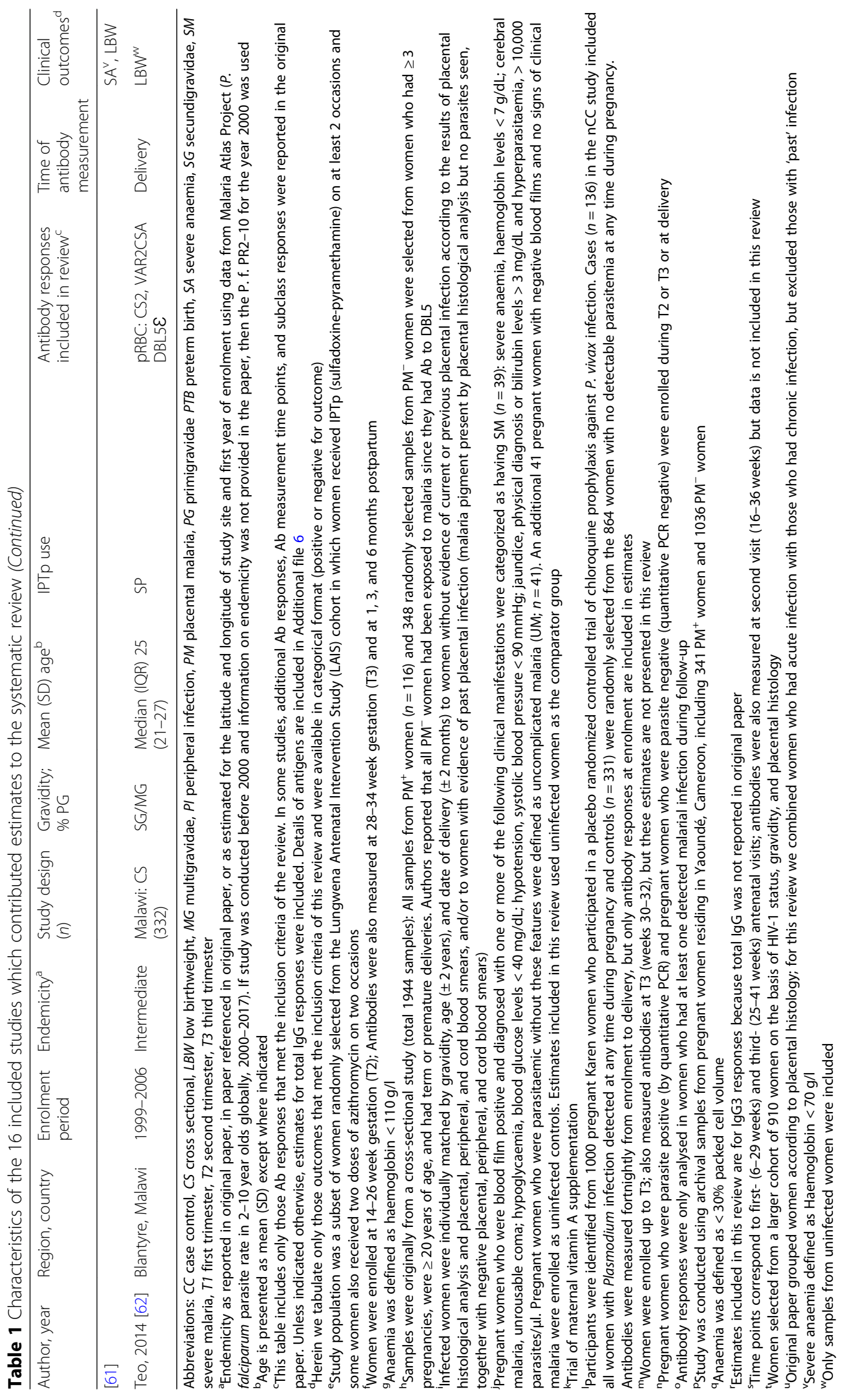




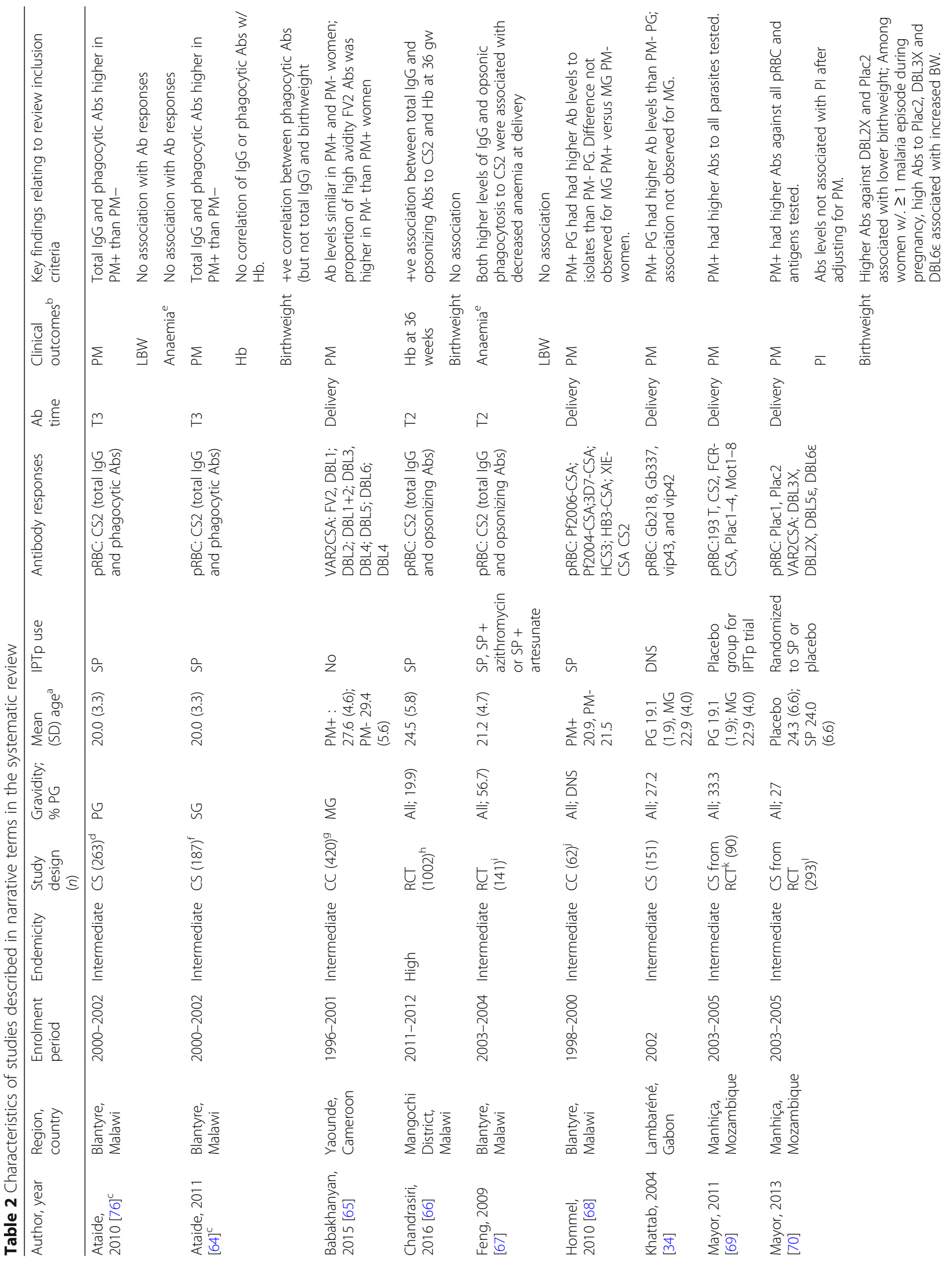




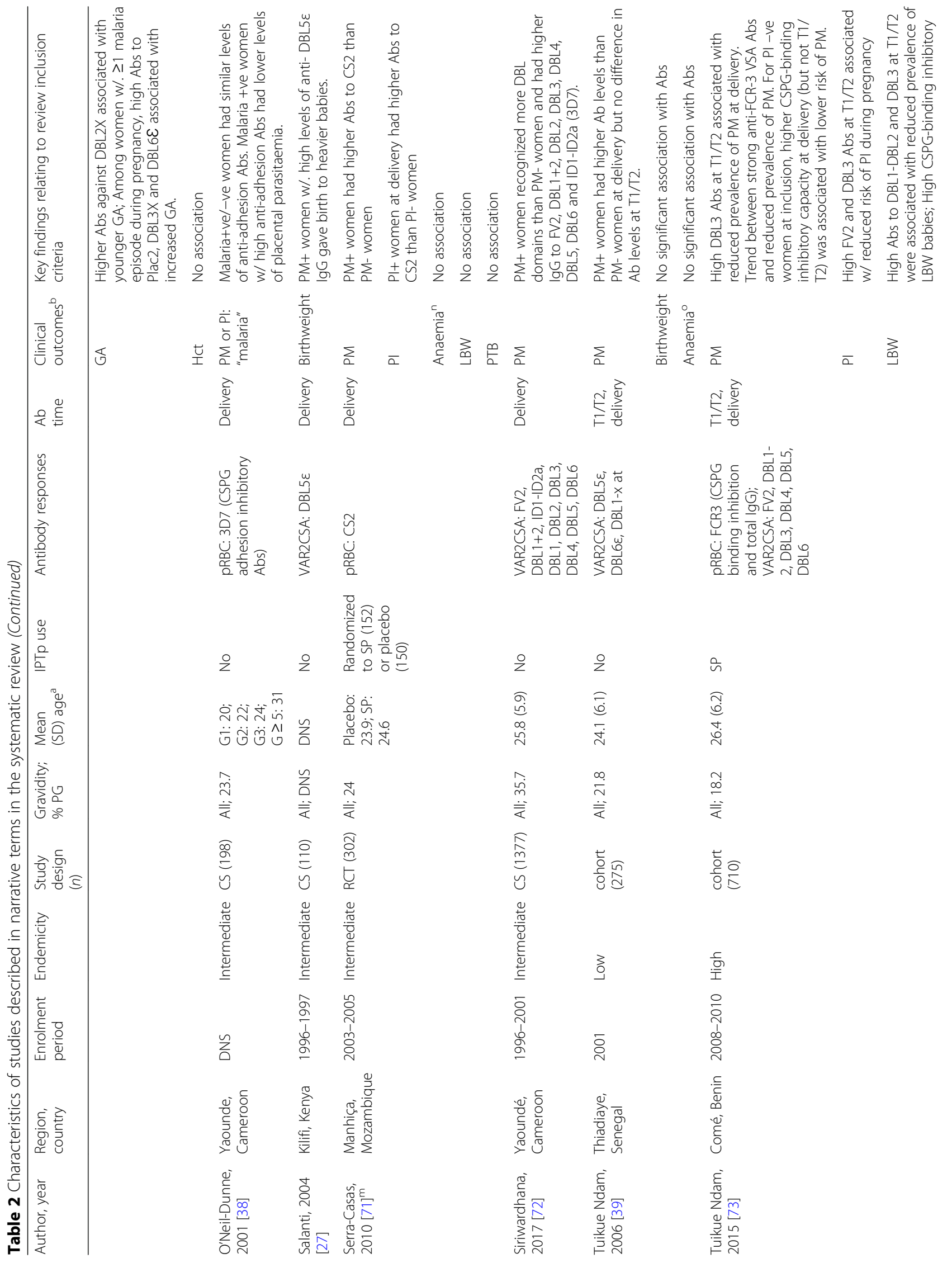




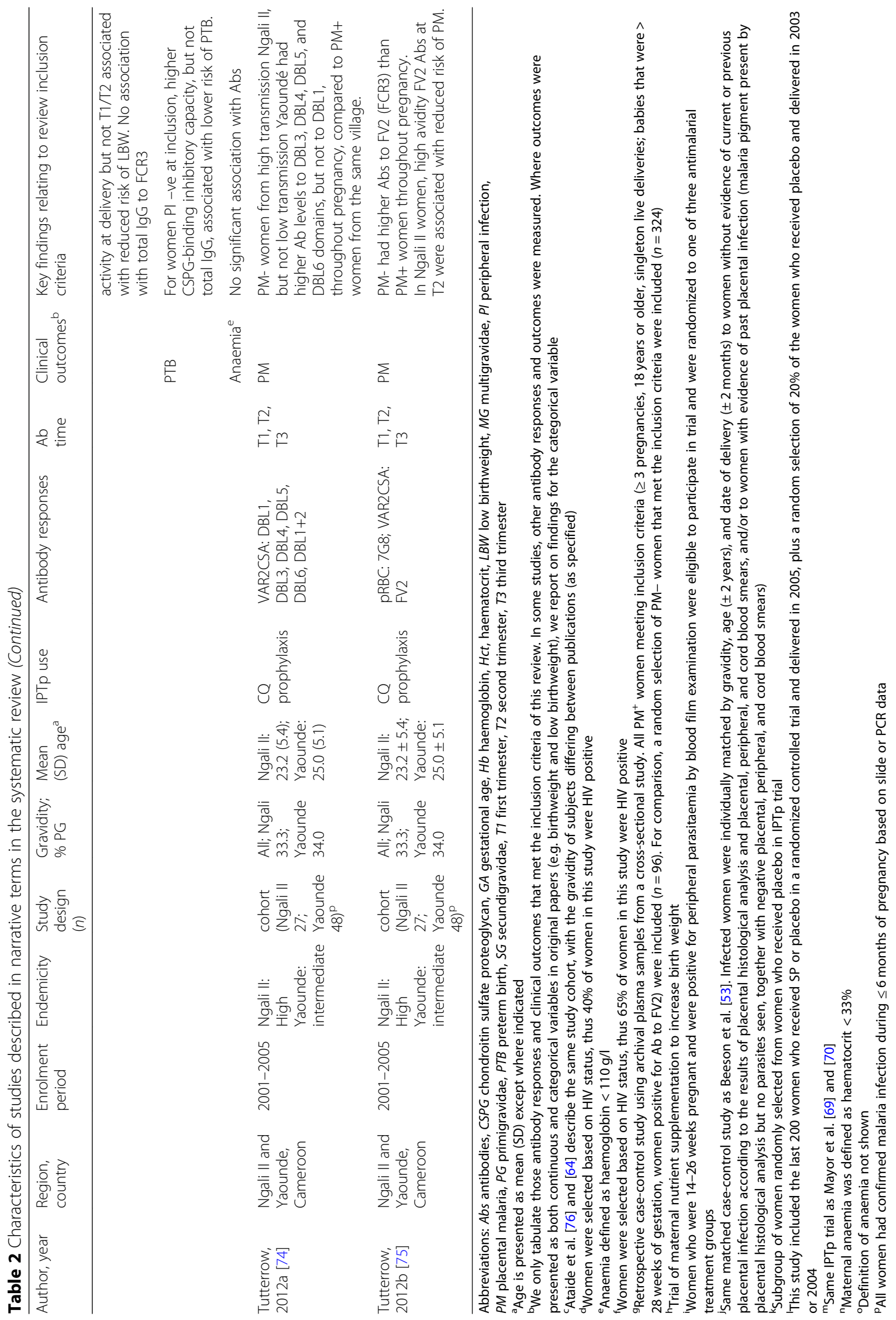


studies reported data from ten countries and the sample sizes ranged from 29 to 1377 participants. Estimates for antibody responses to the following antigens were included: pregnancy-associated pRBC, including CSAadherent lines and isolates taken from infected placentas; full-length VAR2CSA (FV2) and VAR2CSA domains including ID1-ID2a, DBL2, DBL3, DBL3X, DBL3-4, DBL4, and DBL5. Details of the antigens included in the review are presented in Additional file 6 . The most commonly examined malaria outcome was placental infection and the most common birth outcome examined was low birthweight (Tables 1 and 2). Herein, we focus on placental infection, peripheral infection, and low birthweight as key outcomes of interest. Additional forest plots and result text are included in Additional file 7 for anaemia (Additional file 7: Figures S1 and S10), severe malaria (Additional file 7: Figure S2), and preterm birth (Additional file 7: Figures S3, 11 and 12).

\section{Placental infection}

We included estimates from nine studies that investigated the association between antibodies (Abs) to pregnancy-specific pRBC or VAR2CSA domains measured at delivery, and placental infection (Fig. 2a) [35, $42,52,53,56,59-61,63]$. In all studies, placental infection was confirmed by slide microscopy of placental blood or placental histology. Most studies demonstrated either no difference in the odds of placental infection in antibody responders compared to non-responders, or increased odds of placental infection in antibody responders at delivery (Fig. 2a). Total IgG responders to variant surface antigens (VSA) on CSA-adherent parasite lines had increased odds of placental infection in pooled estimates from cross-sectional studies [35] [61] (reOR = 2.25, 95\% CI 0.99-5.13, $I^{2}=46.8 \%$ ) (Fig. 2a) and in a case-control study (OR 3.91, 95\% CI 1.71-8.97) [53]. Functional antibodies to CS2 (agglutinating, CSA adhesion inhibitory) were associated with increased odds of placental infection [53] in a Malawian case-control study (OR of 8 and 2.9 fold, respectively). In contrast, a Kenyan cross-sectional study showed that women who had antibodies that could inhibit adhesion of a placental isolate to CSA had a $62 \%$ reduction in odds of placental infection (OR 0.38, 95\% CI 0.19-0.76) [56] (Fig. 2a). Antibody responders to FV2, and VAR2CSA domains, with the exception of DBL4, had increased odds of placental infection compared to nonresponders [42, 52, 59, 60, 63] (Fig. 2a). Estimates for women sub-grouped by parity showed similar patterns of association between antibody responses at delivery and placental infection (Additional file 7: Figures S4A and S5A).
Twelve studies included in narrative terms measured antibodies at delivery or in the third trimester and examined placental infection as an outcome [34, 38, 39, 64, $65,68-73,76]$. Nine of these studies found that Abs to pregnancy-specific $\mathrm{pRBC}$ and VAR2CSA antigens were positively associated with placental infection or placental parasite density $[34,39,64,68-76,76]$, but in some studies, this relationship was restricted to gravidity group, most commonly in primigravidae [34, 68] (Table 2). One study reported no significant difference in total levels of VAR2CSA antibodies at delivery, but higher levels of high avidity Abs to FV2 in women who were negative for placental infection compared to those who were positive for placental infection (Table 2) [65]. A Cameroonian cross-sectional study reported that among malaria-positive women, those with high antiadhesion Abs had reduced placental parasitaemia, but levels of anti-adhesion Abs were similar between women positive and negative for malaria [38]. To summarize, evidence from studies included in narrative terms suggests that whilst high avidity Abs and anti-adhesion Abs measured at delivery may be associated with protection from placental infection [65] and reduced placental parasitaemia [38], respectively, total IgG responses to VAR2CSA antigens and pregnancy-specific pRBC are positively associated with the presence of placental malaria $[34,39,64,68-72,76]$.

Three prospective studies, including one RCT [55] and two cohort studies [42, 59], provided estimates for the association between antibody responses measured during pregnancy and risk of placental infection, but no clear pattern of association was found (Fig. $2 \mathrm{~b}$ and Additional file 7: Figures S4B and S5B). Of the three cohort studies included in narrative terms, two provided evidence for an association between $\mathrm{Ab}$ responses to some, but not all VAR2CSA domains, and $\mathrm{pRBC}$ strains, measured earlier in pregnancy, and reduced risk of placental infection [73, 75], and one indicated no difference in Ab levels to VAR2CSA domains measured in first or second trimester (T1/T2) among women who were negative or positive for placental infection (Table 2) [39]. Overall, the majority of estimates included in this review, and studies included in narrative terms, indicate that when measured at delivery, antibody responses to pregnancy-specific pRBC and VAR2CSA antigens are associated with the presence of placental infection and may therefore represent markers of infection, rather than correlates of protection. Of the five studies that measured antibodies earlier in pregnancy, and followed women until delivery, two provided evidence for a protective effect of anti-VAR2CSA antibodies [73-75] and three found no significant association with placental infection $[42,55,59]$. 
A

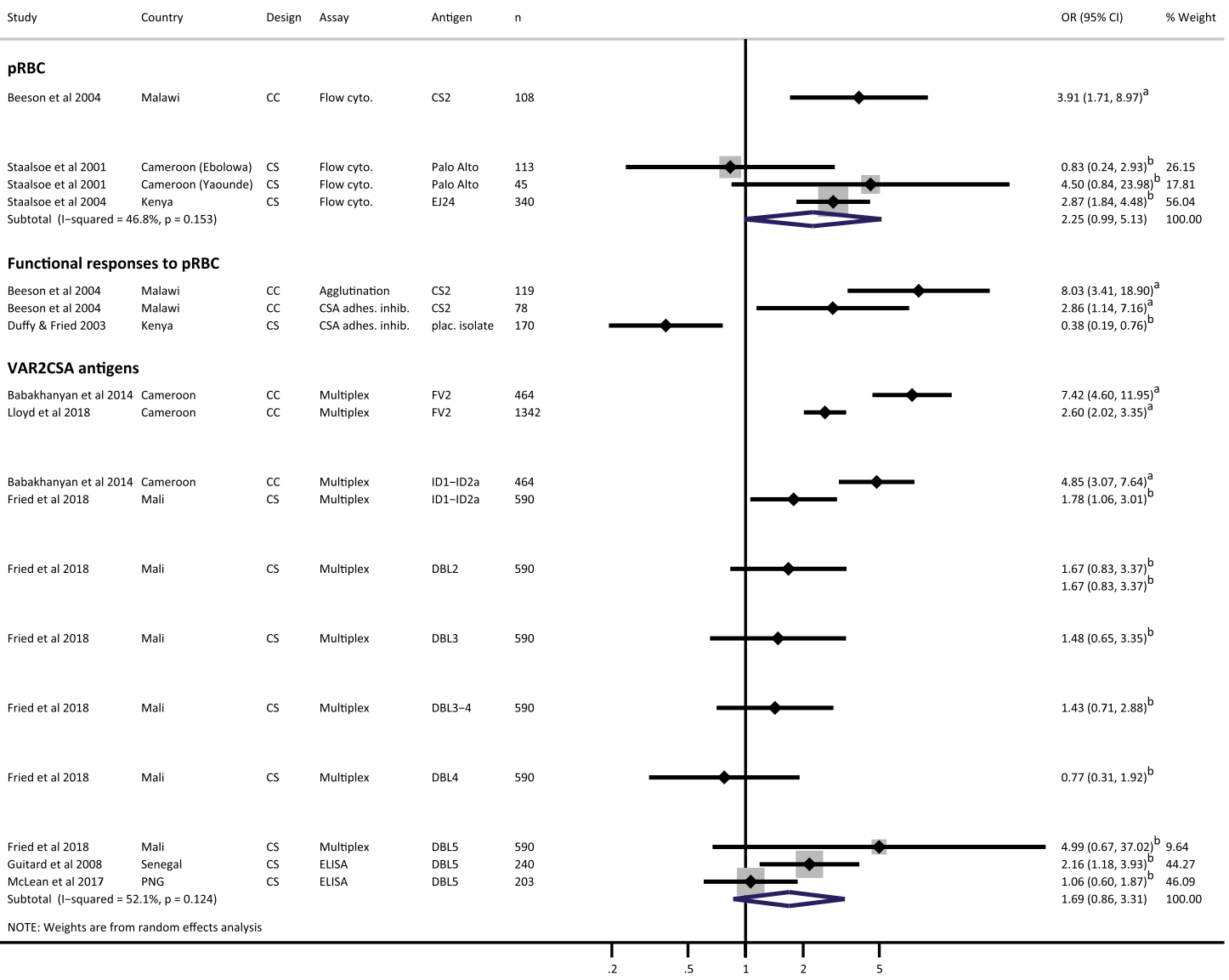

B

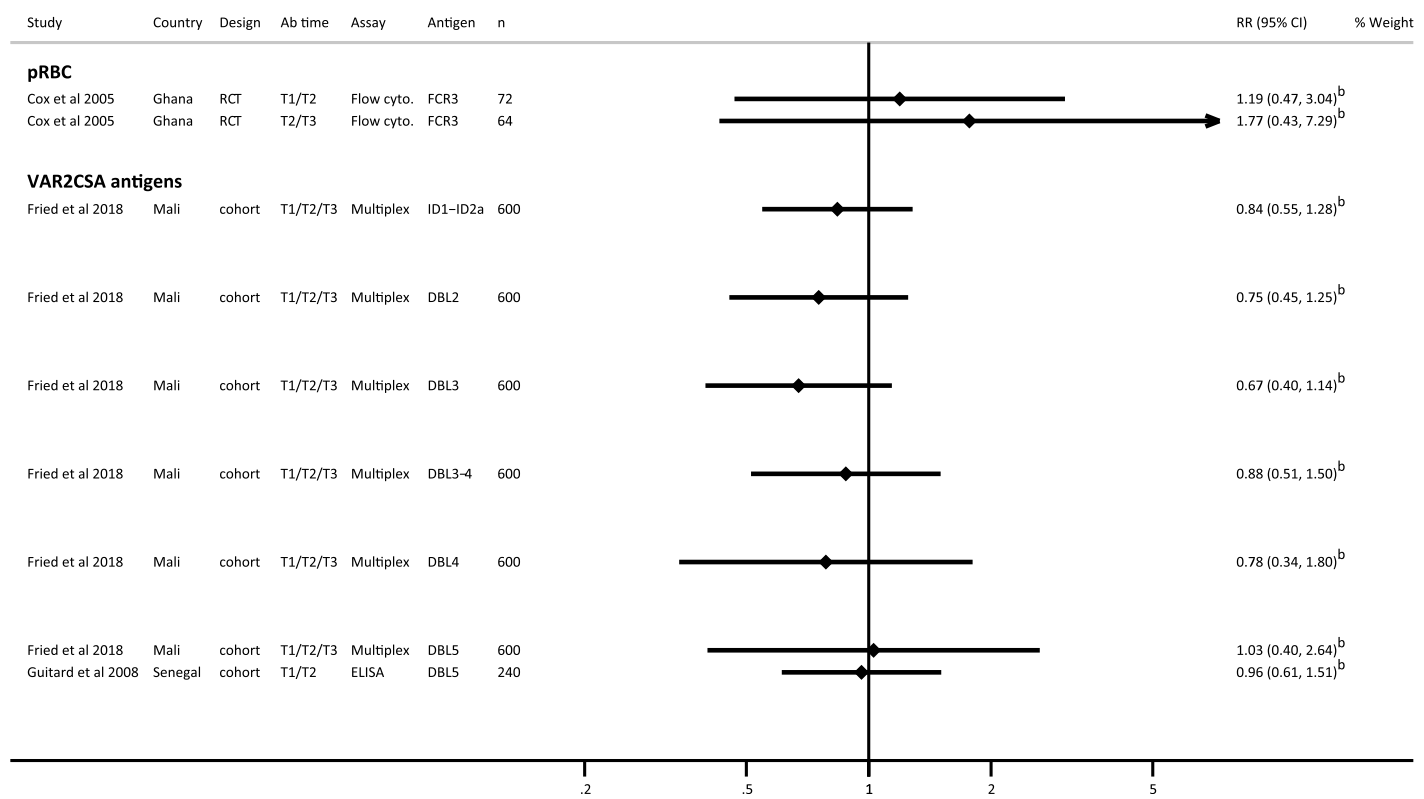

Fig. 2 (See legend on next page.) 
(See figure on previous page.)

Fig. 2 Forest plot of the association between antibodies to pregnancy-associated $P$. falciparum antigens and placental malaria. a Estimates represent the odds of placental malaria in Ab responders compared with Ab non-responders, where antibodies were measured at delivery (cross-sectional studies). $\mathbf{b}$ Estimates represent the relative risk of placental malaria in Ab responders compared to Ab non-responders, where antibodies were measured at various times during pregnancy, as indicated (prospective studies). Estimates are for all gravidities included in original studies. Staalsoe et al. (Yaounde site) included secundigravidae and multigravidae only; Babakhanyan et al. [52] included multigravidae only; and Cox et al. [55] included primigravidae only. Estimate for McLean et al. [63] represents lgG3 responders only as total lgG was not available. Meta-analysis was only performed on estimates where VAR2CSA antigen or functional assay (where applicable) and timing of antibody determination were the same. Meta-analysis of Ab responses to FV2 and odds of PM showed a high degree of heterogeneity $\left(P^{2}=93.1 \%, P<0.001\right)$ so results were not pooled. ${ }^{\mathrm{a} E s t i m a t e}$ calculated by current authors from data in original publication; 'D Data supplied by original authors and estimate calculated by current authors. CC, case-control; CS, cross-sectional; CSA adhes. inhib., CSA adhesion inhibition assay; flow cyto., flow cytometry; n, number of participants included in estimate; OR, odds ratio; plac. isolate, placental isolate; $\mathrm{PRBC}$, parasitized red blood cells; $\mathrm{RCT}$, randomized controlled trial; RR, risk ratio

\section{Peripheral $P$. falciparum infection}

Seven studies provided cross-sectional estimates for the association between antibody responses to pregnancyspecific antigens, measured at various time points, and peripheral $P$. falciparum infection, yielding heterogeneous results (Fig. 3a and Additional file 7: Figures S6A and S7A) [42, 43, 51, 55, 58, 61, 63]. For many of the antigens examined, antibody responders had increased odds of peripheral infection compared to nonresponders, but these associations were rarely significant. Early in pregnancy (T1/T2), antibody responders to CS2-adherent FCR3 had increased odds of peripheral infection in pooled estimates from cross-sectional studies (reOR 2.20, 95\% CI 1.05-4.63, $I^{2}=35.2 \%$ ) (Fig. 3a) [43, 55]. Similarly, antibody responders to a placental isolate at delivery had twofold increased odds of peripheral infection (OR 2.05, 95\% CI 1.29-3.25) [61].

Three studies included in narrative terms examined peripheral $P$. falciparum infection as an outcome [70, $71,73]$. In an IPTp trial in Mozambique, women who were parasitaemic at delivery had higher Abs to CS2 than non-parasitaemic women [71], but antibody levels to a suite of placental isolates and VAR2CSA domains were not associated with peripheral infection after adjusting for placental malaria [70]. In women from Benin, high FV2 and DBL3 Abs early in pregnancy (T1/ T2) were associated with reduced risk of peripheral infection during pregnancy, but this association was not observed for the four other VAR2CSA domains analysed nor to CSPG-binding inhibitory Abs to FCR-3 [73].

In addition to studies that provided cross-sectional estimates, four prospective studies and one nested case-control study provided estimates for the association between antibody responses earlier in pregnancy, and risk of peripheral parasitaemia later in pregnancy or at delivery (Fig. $3 \mathrm{~b}$ and Additional file 7 : Figures S6B and S7B) [42, 43, 51, 55, 57]. One study found that Thai women positive for antibodies to DBL5 in the first trimester had increased odds of having a peripheral infection during pregnancy (OR 5.60, 95\% CI 3.46-9.08) [57], but the remaining studies showed no clear association between positive $\mathrm{Ab}$ responses to pregnancy-specific antigens and prospective risk of peripheral infection [42, 43, 51, 55].

In summary, whilst some studies found an association between $\mathrm{Ab}$ responses to pregnancy-specific $\mathrm{pRBC}$ and VAR2CSA antigens and presence of parasitaemia, either concurrently or at a later time point in pregnancy, we found no evidence for a protective association between these antibodies and peripheral parasitaemia. Thus, antibodies to VAR2CSA either early in pregnancy or at delivery do not appear to reduce the incidence or level of peripheral parasitaemia throughout pregnancy.

\section{Low birthweight}

The association of antibodies to pregnancy-specific $\mathrm{pRBC}$, measured at delivery, and low birthweight was examined in three studies (Fig. 4a and Additional file 7: Figures S8A and S9A): two studies measured total IgG antibodies [61, 62] and one study measured CSA adhesion inhibitory antibodies [56]. Pooled analyses indicated that compared to non-responders, IgG responders to CSA-binding pRBC, measured at delivery, had a clinically significant $26 \%$ reduction in the odds of low birthweight delivery (reOR = $0.74,95 \%$ CI $0.51-1.06, I^{2}=0.0 \%$ ), but the confidence interval was wide and captured a scenario of a small increase in odds of low birthweight (Fig. 4a) [61, 62]. Kenyan women with anti-CSA adhesion activity had an $77 \%$ reduction in odds of low birthweight birth [56] compared to women who did not have anti-CSA adhesion activity. This association was also observed in sub-group analysis of secundigravidae/multigravidae (Additional file 7: Figure S9A) but not among primigravidae (Additional file 7: Figure S8A), most likely because an insufficient number of women had acquired anti-adhesion activity in their first pregnancy in this study population. In contrast, there was no significant pattern of association between antibody responses to VAR2CSA antigens measured at delivery and low birthweight (Fig. 4a) [42, 60, 62]. Estimates stratified by gravidity gave similarly heterogeneous results for association between antibodies to VAR2CSA at delivery and low birthweight (Additional file 7: Figures S8A and S9A).

When antibodies were measured earlier in pregnancy, estimates from one study of Malian women indicated 


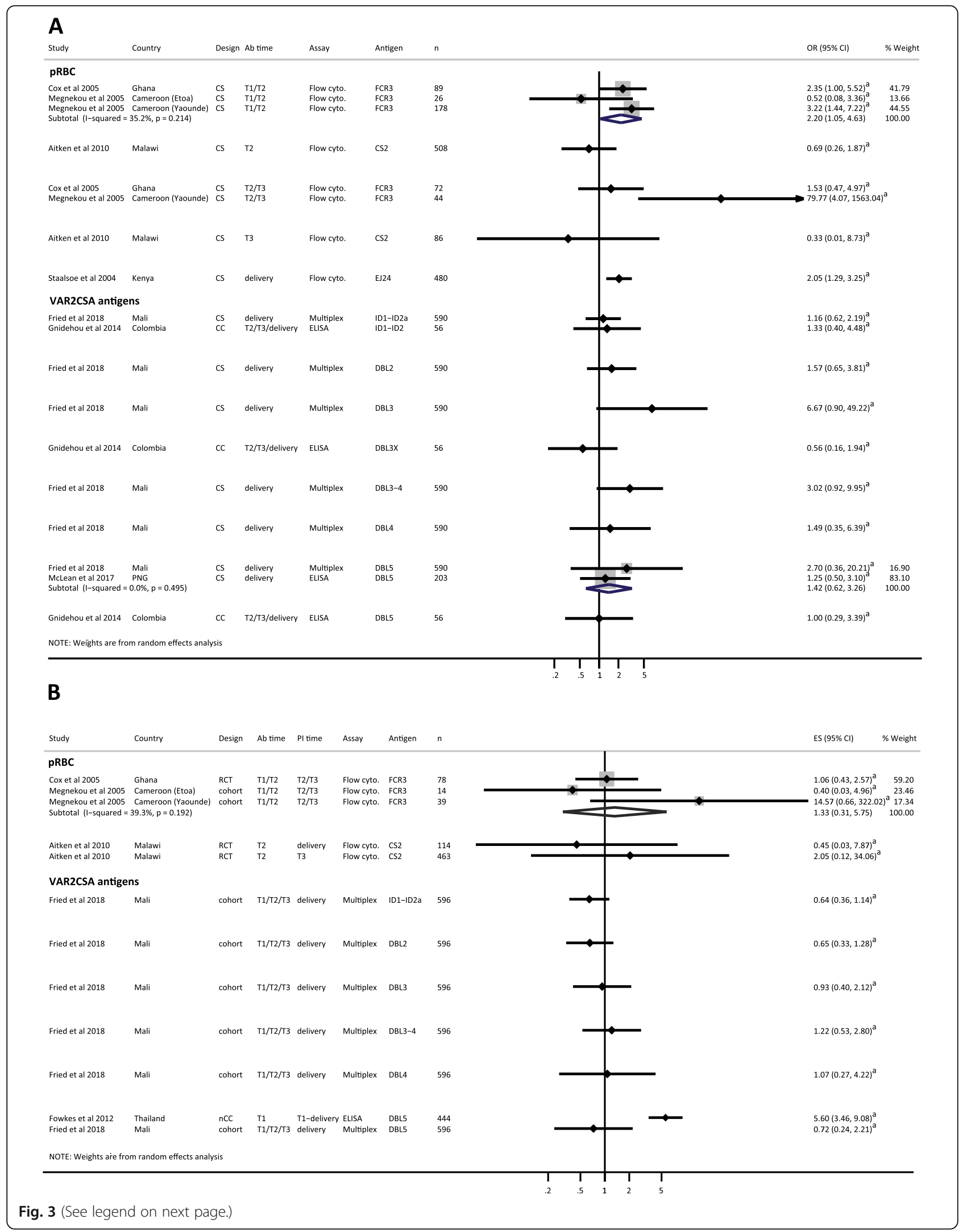


(See figure on previous page.)

Fig. 3 Forest plot of the association between antibodies to pregnancy-associated $P$. falciparum antigens and peripheral parasitaemia. a Estimates represent the odds of peripheral $P$. falciparum parasitaemia in Ab responders compared to Ab non-responders, where antibodies were measured at the same time point as parasitaemia (cross-sectional studies). b Estimates of peripheral $P$. falciparum parasitaemia in Ab responders compared to Ab non-responders, where antibodies were measured at time points prior to parasitaemia determination. Estimates are risk ratios for RCT and cohort studies and odds ratio for the nested case-control study. Estimates are for women of all gravidities included in original studies: Cox et al. [55] included primigravidae only. The timing of antibody and parasitaemia determination is indicated. Estimate for McLean et al. [63] represents lgG3 responders only as total lgG was not available. DBL5 estimates were only combined when study design was the same. Estimates for FCR3

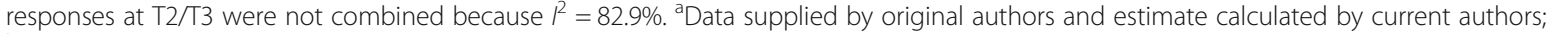
bEstimate calculated by current authors from data in original publication. CC, case control; CS, cross-sectional; ES, estimate; n, number of participants included in estimate; Flow cyto., flow cytometry; nCC, nested case-control; OR, odds ratio; PI time, timing of determination of parasitaemia; $\mathrm{PRBC}$, parasitized red blood cells; RCT, randomized controlled trial; $\mathrm{T} 1$, first trimester; $\mathrm{T} 2$, second trimester; $\mathrm{T} 3$, third trimester

that $\mathrm{Ab}$ responders to ID1-ID2a but not DBL2, DBL3, DBL3-4, DBL4, and DBL5 had increased risk of low birthweight births (RR 1.98, 95\% CI 1.13-3.48) compared to non-responders (Fig. 4b). In a sub-group analysis, this association remained significant in primigravidae (Additional file 7: Figure S8B) but not multigravidae (Additional file 7: Figure S9B) [42].

Of the studies included in narrative terms, high antibody responses to some VAR2CSA antigens including DBL5 $\varepsilon$ [27], DBL1-DBL2, and DBL3 [73] and functional antibodies to pRBC $[64,73]$, were associated with reduced risk of low birthweight (or Ab levels were correlated with birthweight), but these associations were dependent on the timing of antibody determination [73] and the gravidity of subjects [64]. In a Senegalese cohort, no significant association was found for antibodies to DBL1-x, DBL5e, and DBL6e, measured at T1/T2 and delivery, and low birthweight [39] (Table 2).

In summary, several studies provided evidence for an association between antibody responses to pregnancyspecific $P$. falciparum antigens and decreased risk of low birthweight [27, 56, 61, 62, 64, 73].

\section{Discussion}

In this systematic review and meta-analysis, we aimed to synthesize the existing epidemiological evidence for the association between antibodies to pregnancy-specific antigens and the risk of malaria in pregnancy and its associated adverse maternal and birth outcomes. Overall, we found that estimates for the association between pregnancy-specific $P$. falciparum antibody responses and the pregnancy and birth outcomes examined were heterogeneous in terms of both the direction and magnitude of effect. Whilst antibody responses to several antigens were positively associated with the presence of placental and peripheral infections, this review did not identify evidence that any specific antibody response is associated with protection from PAM and its clinical consequences across multiple populations.

Cross-sectional estimates for the association between antibody responses and $P$. falciparum infections during pregnancy suggest that antibody responses may serve as markers of current infections. Indeed, previous studies have reported a concurrent increase in pregnancyspecific antibodies in women with placental infection $[53,61,69,70]$. We found that positive antibody responses to pregnancy-specific antigens were associated with increased odds of peripheral infection in some studies, with varying degrees of significance $[43,55,57$, 61]. At delivery, antibody responders (IgG) to the pRBC surface $[35,53,61]$, to full-length VAR2CSA (FV2) [52, $60]$, and to the vaccine candidate ID1-ID2a, which includes interdomain region $1, \mathrm{DBL} 2 \mathrm{X}$, and interdomain region $2 \mathrm{a}$, had increased odds of placental infection compared to non-responders [42, 52] (Fig. 2a). In contrast, antibodies to single domains (DBL2, DBL3, DBL4, DBL5), measured at delivery, were not associated with placental infection (Fig. 2a). This finding suggests that reactivity to VAR2CSA epitopes in their native formation may be more relevant correlates of disease than responses to individual recombinant domains. Indeed, previous in vitro studies using the full-length extracellular VAR2CSA have suggested that the overall folding of the protein may be important for ability to bind CSA $[77,78]$. Furthermore, it has been suggested that functional antibodies to VAR2CSA may have affinity to conformational epitopes not displayed by individual recombinant constructs from single alleles [79]. Further studies designed to measure antibody responses to multiple VAR2CSA antigens concurrently, will be essential to confirm which antibody responses are the best markers of infection and could therefore be utilized as serosurveillance tools [80].

An effective vaccine against placental malaria should induce broadly active and strain-transcending antibodies to block the adhesion of VAR2CSA-expressing parasites to CSA [81, 82]. A single cross-sectional study found that women positive for CSA-binding inhibitory antibodies had significantly decreased odds of placental infection, as well as low birthweight and preterm birth [56]. Although two vaccines based on the N-terminal CSA-binding region of VAR2CSA are currently in early clinical trials, this review highlights a scarcity of evidence for a protective association between antibodies to 


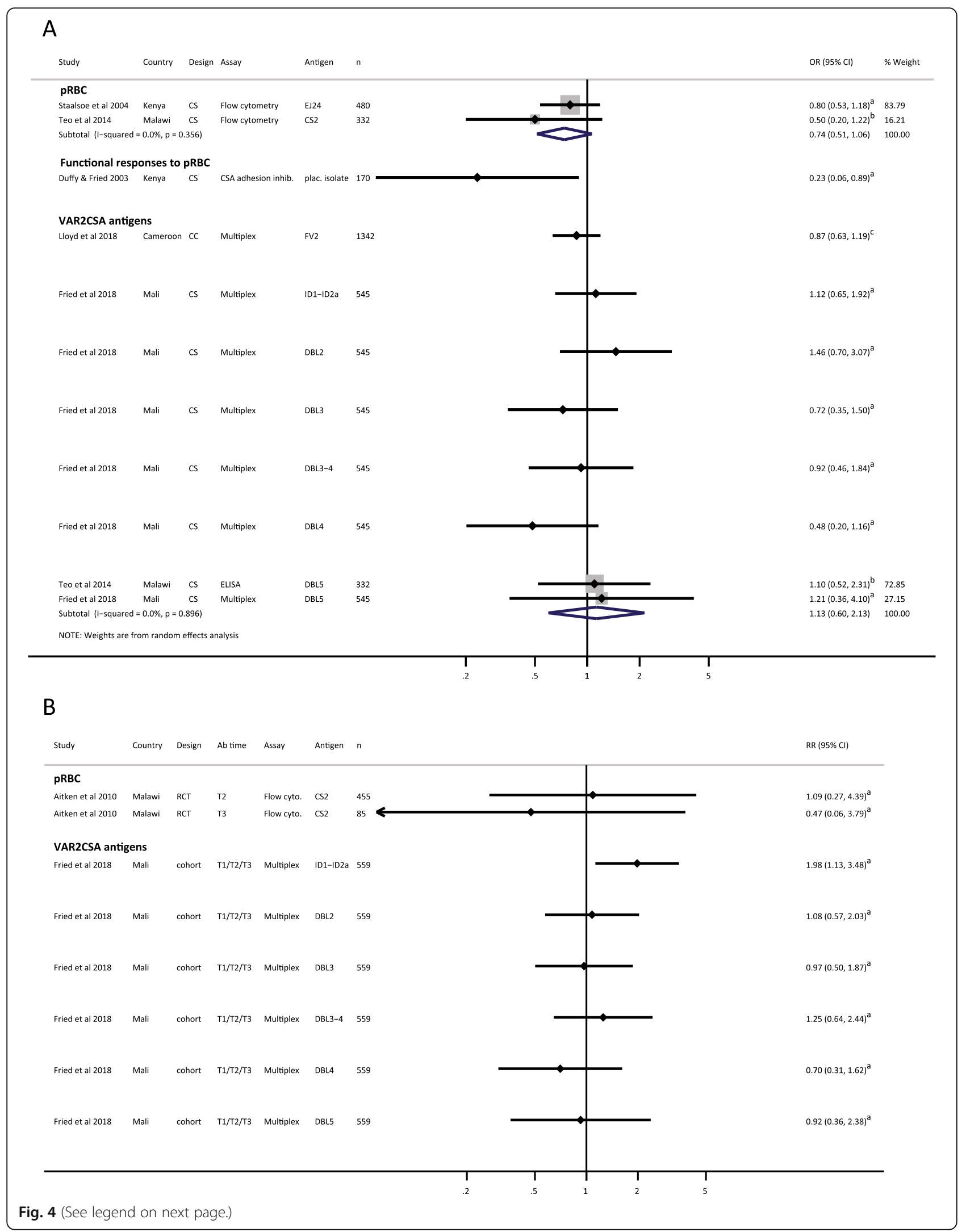


(See figure on previous page.)

Fig. 4 Forest plot of the association between antibodies to pregnancy-associated P. falciparum antigens and low birthweight. a Estimates represent the odds of low birthweight birth in Ab responders compared with Ab non-responders, where antibodies were measured at delivery (cross-sectional studies). b Estimates represent the risk of low birthweight in Ab responders compared with Ab non-responders, where antibodies were measured at time points prior to delivery, as indicated (prospective studies). Estimates are for women of all gravidities included in the original studies. Teo et al. included secundigravidae and multigravidae only. ${ }^{2}$ Data supplied by original authors and estimate calculated by current authors; ${ }^{b}$ Estimate provided by original author; ${ }^{C}$ Estimate calculated by current authors from data in original publication. CC, case-Control; CS, cross-sectional; $n$, number of participants included in estimate; OR, odds ratio; pRBC, parasitized red blood cells; RCT, randomized controlled trial; $R R$, risk ratio; $T 1$, first trimester; $T 2$, second trimester; $T 3$, third trimester

recombinant VAR2CSA domains, including the vaccine candidates, and placental malaria. Only two prospective cohort studies, included in narrative terms, found that antibody responses to selected VAR2CSA antigens and pRBC were associated with protection from placental infection [73-75] and responses to individual recombinant VAR2CSA antigens were associated with protection against low birthweight and preterm birth in individual studies only [27, 73]. None of these studies reported an association between antibodies to the vaccine candidates (ID1-DBL2X-ID2a and DBL1X-DBL2X) and protection from placental malaria, low birthweight, or preterm birth. Interestingly, Malian primigravidae who were positive for antibodies to ID1-ID2a at enrolment (during T2/ T3) were more likely to deliver preterm babies, suggesting that this antigen may be a marker of parasite exposure [42]. It is likely that protection from placental malaria and its associated adverse pregnancy outcomes develops with the acquisition of an increasingly broad antibody response to different VAR2CSA domains and allelic variants, rather than to a single domain [74, 75]. Furthermore, high avidity antibodies and functional antibody responses are probably more important measures than simple quantification of IgG responses to recombinant proteins $[65,75]$.

In the absence of a robust, cross-population estimate of the effect of pregnancy-specific $P$. falciparum antibody responses, we are unable to quantify the fraction of clinical disease or adverse birth outcomes that may be averted by these immune responses. This has implications for understanding any impact of potential vaccines based on pregnancy-specific antigens on the burden of pregnancy-associated malaria in a given population. Only nine of the studies examined antibody responses to multiple recombinant antigens concurrently in the same populations $[39,42,52,58,65,70,72-74]$, and only three of these contributed estimates in the format required for meta-analysis $[42,52,58]$. This precluded assessment of the relative clinical importance of antibody responses to individual VAR2CSA domains.

A key strength of this systematic review was that we contacted authors directly, and for 13 studies, we were able to obtain estimates that were not originally published. A limitation was the heterogeneity observed between estimates, which is likely due to methodological and epidemiological differences between the included studies. We included studies that collectively examined a broad range of antibody responses, including to the surface of $\mathrm{pRBC}$ isolates from infected placentas, to CSAbinding $\mathrm{pRBC}$ strains, and to recombinant VAR2CSA antigens. With respect to the antigens examined, parasite isolates differed in their geographical origin and recombinant antigens varied by allele, domain boundary, and expression system (Additional file 6), potentially impacting variation in antibody reactivity between studies $[83,84]$. Importantly, the influence of the global genetic diversity of the var2csa gene on antibody reactivity, and consequently, vaccine development, has not been adequately determined [84]. Furthermore, inconsistencies in estimates across studies may reflect a dual role for antibodies to VAR2CSA, whereby antibodies contribute to protective immunity via blocking of $\mathrm{pRBC}$ adhesion to CSA, but also contribute to local pathology by activating inflammatory monocytes and macrophages in the placenta $[85,86]$. In addition, differences in the methodology employed to measure antibody responses may have contributed to heterogeneity in estimates. Furthermore, due to the limited availability of stratified data, we only presented estimates for women sub-grouped into primigravidae and secundigravidae/multigravidae groups. In some earlier studies, antibodies to pregnancyspecific $P$. falciparum antigens were associated with improved pregnancy outcomes in secundigravidae only [56], or in women with chronic pregnancy-associated malaria infections [61]. Therefore, further studies examining antibody responses in specific parity and clinical groups may be warranted.

Due to the breadth of study designs and antigens examined, in most cases estimates for the association between a specific antibody response and clinical outcome across different populations could not be pooled. Importantly, estimates for the association between antibody responses and PAM outcomes derived from a single population may not be generalizable to other malaria-endemic areas. We identified a lack of cohort studies examining associations between antibody responses and prospective risk of malaria in pregnancy. The majority of the included estimates 
were derived from cross-sectional analyses, usually at delivery, thus limiting the ability to establish a causal relationship between antibody responses and PAM outcomes. Moreover, measurements of immunity inferred by antibody levels at a single time point can be misleading as antibody production is highly dynamic [39, 51, 57, 87]. Importantly, many of the studies were not originally designed to detect differences in the risk of placental infection and associated outcomes between antibody responders and nonresponders and were therefore not statistically powered to detect such associations.

Study populations varied with respect to the proportion of primigravidae versus multigravidae, the percentage of women receiving intermittent preventive treatment in pregnancy (IPTp), the prevalence of HIV and other infectious diseases, the transmission intensity of the study site, and the malaria exposure history of the women. Both parity and transmission intensity can influence the kinetics of antiVAR2CSA antibody responses during pregnancy [35, 38, 39, 73]. Moreover, the transmission intensity may affect the relationship between antibody responses and PAM [74, 75] as women living in areas of stable/intense malaria transmission may develop a broader repertoire of functional antibody responses to pregnancy-associated $P$. falciparum earlier in pregnancy, than women facing low/seasonal transmission [74]. Because antibody responses to the same antigen were rarely examined across multiple populations using comparable study designs, it was difficult to assess the effect of transmission intensity. Understanding the impact of transmission intensity on acquired immunity has implications for both serosurveillance and vaccine development.

\section{Conclusion}

Overall, this systematic review found that pregnancyspecific $P$. falciparum antibody responses likely serve as markers of exposure to malaria in pregnancy, rather than correlates of protection. In order to objectively identify and prioritize antigens for vaccine development, it is important to demonstrate that a candidate antigen is a specific target of immune responses associated with protection from symptomatic disease in naturally exposed populations [88, 89]. Rational vaccine design and the development of immuno-serosurveillance tools would benefit from additional prospective cohort studies examining antibody responses early in pregnancy and at multiple time points throughout to a broad range of pregnancy-specific $P$. falciparum antigens across different epidemiological settings.

\section{Supplementary information}

Supplementary information accompanies this paper at https://doi.org/10. 1186/s12916-019-1467-6.

\author{
Additional file 1. Prisma 2009 Checklist. \\ Additional file 2. Full search strategy for Pubmed database. \\ Additional file 3. Data extraction form. \\ Additional file 4. Risk of bias assessment. \\ Additional file 5. Excluded studies. \\ Additional file $\mathbf{6}$. Details of parasites and recombinant antigens \\ featured in review. \\ Additional file 7. Supplementary forest plots and results for additional
} outcomes.

\section{Acknowledgements}

We wish to thank Elizabeth Aitken, Ricardo Ataide, Anna Babakhanyan, James Beeson, Sharon Cox, Philippe Deloron, Michael Duffy, Patrick Duffy; Gaoqian Feng, Michal Fried, Sedami Gnidehou, Channe Gowda, Lars Hviid, Anthony Jaworowski, Ayman Khattab, Alfredo Mayor, Alistair McLean, Stephen Rogerson, Ali Salanti, Diane Wallace Taylor, Andrew Teo, and Nicaise Tuikue Ndam for responding to requests for further information about their original studies, which were screened for inclusion in this review. We are particularly grateful to Elizabeth Aitken, Sharon Cox, Patrick Duffy, Michal Fried, Sedami Gnidehou, Lars Hviid, Alistair McLean, Nicaise Tuikue Ndam, and Andrew Teo who kindly took the time to send us data from their original studies in a format that enabled us to include it in this review. We wish to thank Alfredo Mayor, Diane Wallace Taylor, and Anna Maria van Eijk for their comprehensive and considered peer review, which greatly improved the manuscript.

\section{Authors' contributions}

JCC, PAA, ZL, RP, KM, BD, JAS, and FJIF agree with the manuscript results and conclusions. JCC, PAA, ZL, RP, JAS, and FJIF designed the study. JCC, ZL, RP, $\mathrm{BD}, \mathrm{PAA}$, and KM collected and analysed the data. JCC wrote the first draft of the paper. JCC, PAA, ZL, JAS, and FJIF contributed to the writing of the paper. All authors approved the final version of the manuscript.

\section{Funding}

This work was supported by the National Health and Medical Research Council of Australia [Career Development fellowship 1166753 (to F.J.I.F.), senior research fellowships 1104975 (to J.A.S.) and the Australian Centre of Research Excellence in Malaria Elimination (ACREME) 1134989], the Australian Research Council [Future Fellowships FT130101122 (to F.J.I.F.), and a Victorian State Government Operational Infrastructure Support grant. The funders had no role in study design, data collection and analysis, decision to publish, or preparation of the manuscript.

Availability of data and materials

The dataset used and analysed during the current study are available from the corresponding author on reasonable request.

Ethics approval and consent to participate

Not applicable.

Consent for publication

Not applicable.

Competing interests

The authors declare that they have no competing interests.

\section{Author details}

${ }^{1}$ Burnet Institute, 85 Commercial Road, Melbourne, Victoria 3004, Australia. ${ }^{2}$ Department of Epidemiology and Preventive Medicine, Monash University, Melbourne, Australia. ${ }^{3}$ Centre for Epidemiology and Biostatistics, Melbourne School of Population and Global Health, The University of Melbourne, Melbourne, Australia. ${ }^{4}$ Department of Infectious Diseases, Monash University, Melbourne, Australia. 
Received: 24 June 2019 Accepted: 11 November 2019

\section{Published online: 16 January 2020}

\section{References}

1. Marsh K, Kinyanjui S. Immune effector mechanisms in malaria. Parasite Immunol. 2006;28(1-2):51-60.

2. Desai M, ter Kuile FO, Nosten F, McGready R, Asamoa K, Brabin B, Newman $\mathrm{RD}$. Epidemiology and burden of malaria in pregnancy. Lancet Infect Dis 2007;7(2):93-104.

3. Brabin BJ, Romagosa C, Abdelgalil S, Menendez C, Verhoeff FH, McGready R, Fletcher KA, Owens S, D'Alessandro U, Nosten F, et al. The sick placenta-the role of malaria. Placenta. 2004;25(5):359-78.

4. Moore KA, Simpson JA, Scoullar MJL, McGready R, Fowkes FJ. Quantification of the association between malaria in pregnancy and stillbirth: a systematic review and meta-analysis. Lancet Glob Health. 2017;5(11):e1101-12.

5. Rogerson SJ, Hviid L, Duffy PE, Leke RF, Taylor DW. Malaria in pregnancy: pathogenesis and immunity. Lancet Infect Dis. 2007;7(2):105-17.

6. McGready R, Lee SJ, Wiladphaingern J, Ashley EA, Rijken MJ, Boel M, Simpson JA, Paw MK, Pimanpanarak M, Mu O, et al. Adverse effects of falciparum and vivax malaria and the safety of antimalarial treatment in early pregnancy: a population-based study. Lancet Infect Dis. 2012;12(5):388-96.

7. Moore KA, Simpson JA, Paw MK, Pimanpanarak M, Wiladphaingern J, Rijken MJ, Jittamala P, White NJ, Fowkes FJI, Nosten F, et al. Safety of artemisinins in first trimester of prospectively followed pregnancies: an observational study. Lancet Infect Dis. 2016;16(5):576-83.

8. McGregor IA, Wilson ME, Billewicz WZ. Malaria infection of the placenta in the Gambia, West Africa; its incidence and relationship to stillbirth, birthweight and placental weight. Trans R Soc Trop Med Hyg. 1983;77(2): 232-44.

9. Shulman CE, Marshall T, Dorman EK, Bulmer JN, Cutts F, Peshu N, Marsh K. Malaria in pregnancy: adverse effects on haemoglobin levels and birthweight in primigravidae and multigravidae. Tropical Med Int Health. 2001;6(10):770-8.

10. Steketee RW, Wirima JJ, Slutsker L, Roberts JM, Khoromana CO, Heymann $\mathrm{DL}$, Breman JG. Malaria parasite infection during pregnancy and at delivery in mother, placenta, and newborn: efficacy of chloroquine and mefloquine in rural Malawi. Am J Tropical Med Hygiene. 1996;55(1 Suppl):24-32.

11. Watkinson M, Rushton DI. Plasmodial pigmentation of placenta and outcome of pregnancy in west African mothers. Br Med J. 1983; 287(6387):251-4.

12. Ataide R, Mayor A, Rogerson SJ. Malaria, primigravidae, and antibodies: knowledge gained and future perspectives. Trends Parasitol. 2014;30(2): 85-94.

13. Walter PR, Garin Y, Blot P. Placental pathologic changes in malaria. A histologic and ultrastructural study. Am J Pathol. 1982;109(3):330-42.

14. Rogerson SJ, Pollina E, Getachew A, Tadesse E, Lema VM, Molyneux ME. Placental monocyte infiltrates in response to Plasmodium falciparum malaria infection and their association with adverse pregnancy outcomes. Am J Trop Med Hyg. 2003;68(1):115-9.

15. Fried M, Duffy PE. Adherence of Plasmodium falciparum to chondroitin sulfate $a$ in the human placenta. Science. 1996;272(5267):1502-4.

16. Parmley RT, Takagi M, Denys FR. Ultrastructural localization of glycosaminoglycans in human term placenta. Anat Rec. 1984;210(3):477-84.

17. Maubert B, Guilbert $\amalg$, Deloron P. Cytoadherence of Plasmodium falciparum to intercellular adhesion molecule 1 and chondroitin-4-sulfate expressed by the syncytiotrophoblast in the human placenta. Infect Immun. 1997;65(4): $1251-7$

18. Beeson JG, Brown GV, Molyneux ME, Mhango C, Dzinjalamala F, Rogerson SJ. Plasmodium falciparum isolates from infected pregnant women and children are associated with distinct adhesive and antigenic properties. J Infect Dis. 1999;180(2):464-72.

19. Chaiyaroj SC, Angkasekwinai P, Buranakiti A, Looareesuwan S, Rogerson SJ, Brown GV. Cytoadherence characteristics of Plasmodium falciparum isolates from Thailand: evidence for chondroitin sulfate a as a cytoadherence receptor. Am J Tropical Med Hygiene. 1996;55(1):76-80.

20. Rogerson SJ, Chaiyaroj SC, Ng K, Reeder JC, Brown GV. Chondroitin sulfate a is a cell surface receptor for Plasmodium falciparum-infected erythrocytes. J Exp Med. 1995;182(1):15-20.

21. Ricke CH, Staalsoe T, Koram K, Akanmori BD, Riley EM, Theander TG, Hviid L. Plasma antibodies from malaria-exposed pregnant women recognize variant surface antigens on Plasmodium falciparum-infected erythrocytes in a parity-dependent manner and block parasite adhesion to chondroitin sulfate a. J Immunol. 2000;165(6):3309-16.

22. Ayres Pereira M, Mandel Clausen T, Pehrson C, Mao Y, Resende M, Daugaard M, Riis Kristensen A, Spliid C, Mathiesen L, E Knudsen L et al: Placental sequestration of Plasmodium falciparum malaria parasites is mediated by the interaction between VAR2CSA and chondroitin sulfate a on Syndecan-1. PLoS Pathog 2016, 12(8):e1005831.

23. Reeder JC, Cowman AF, Davern KM, Beeson JG, Thompson JK, Rogerson SJ, Brown GV. The adhesion of Plasmodium falciparum-infected erythrocytes to chondroitin sulfate $a$ is mediated by $P$. falciparum erythrocyte membrane protein 1. Proc Natl Acad Sci U S A. 1999;96(9):5198-202.

24. Duffy MF, Maier AG, Byrne TJ, Marty AJ, Elliott SR, O'Neill MT, Payne PD, Rogerson SJ, Cowman AF, Crabb BS, et al. VAR2CSA is the principal ligand for chondroitin sulfate a in two allogeneic isolates of Plasmodium falciparum. Mol Biochem Parasitol. 2006;148(2):117-24.

25. Viebig NK, Levin E, Dechavanne S, Rogerson SJ, Gysin J, Smith JD, Scherf A, Gamain B. Disruption of var2csa gene impairs placental malaria associated adhesion phenotype. PLoS One. 2007;2(9):e910.

26. Salanti A, Staalsoe T, Lavstsen T, Jensen AT, Sowa MP, Arnot DE, Hviid L. Theander TG: Selective upregulation of a single distinctly structured var gene in chondroitin sulphate A-adhering Plasmodium falciparum involved in pregnancy-associated malaria. Molecular Microbiol. 2003;49(1):179-91.

27. Salanti A, Dahlback M, Turner L, Nielsen MA, Barfod L, Magistrado P, Jensen ATR, Lavstsen T, Ofori MF, Marsh K, et al. Evidence for the involvement of VAR2CSA in pregnancy-associated malaria. J Exp Med. 2004;200(9):1197-203.

28. Clausen TM, Christoffersen S, Dahlback M, Langkilde AE, Jensen KE, Resende M, Agerbaek MO, Andersen D, Berisha B, Ditlev SB, et al. Structural and functional insight into how the Plasmodium falciparum VAR2CSA protein mediates binding to chondroitin sulfate a in placental malaria. J Biol Chem. 2012;287(28):23332-45

29. Bigey P, Gnidehou S, Doritchamou J, Quiviger M, Viwami F, Couturier A Salanti A, Nielsen MA, Scherman D, Deloron P, et al. The NTS-DBL2X region of VAR2CSA induces Cross-reactive antibodies that inhibit adhesion of several Plasmodium falciparum isolates to chondroitin sulfate a. J Infect Dis. 2011;204(7):1125-33.

30. Bordbar B, Tuikue-Ndam N, Bigey P, Doritchamou J, Scherman D, Deloron P. Identification of Id1-DBL2X of VAR2CSA as a key domain inducing highly inhibitory and cross-reactive antibodies. Vaccine. 2012;30(7):1343-8.

31. Gbedande K, Fievet N, Viwami F, Ezinmegnon S, Issifou S, Chippaux JP, Dossou Y, Moutairou K, Massougbodji A, Ndam N, et al. Clinical development of a VAR2CSA-based placental malaria vaccine PAMVAC: quantifying vaccine antigen-specific memory B \& T cell activity in Beninese primigravidae. Vaccine. 2017;35(27):3474-81.

32. ClinicalTrials.gov. Bethesda (MD): National Library of Medicine (US). Identifier NCT02647489, Safety and Immunogenicity of the Placental Malaria Vaccine Candidate PAMVAC Variously Adjuvanted (PAMVAC); Available from: https:// clinicaltrials.gov/ct2/show/NCT02647489. Accessed 2 Mar 2019.

33. ClinicalTrials.gov. Bethesda (MD): National Library of Medicine (US). Identifier NCT02658253, Trial to Evaluate the Safety and Immunogenicity of a Placental Malaria Vaccine Candidate (PRIMVAC) in Healthy Adults (PRIMALVAC); Available from: https://clinicaltrials.gov/ct2/show/NCT0265 8253?term=primvac\&draw=2\&rank=1. Accessed 2 Mar 2019.

34. Khattab A, Reinhardt C, Staalsoe T, Fievet N, Kremsner PG, Deloron P, Hviid $L$, Klinkert MQ. Analysis of IgG with specificity for variant surface antigens expressed by placental Plasmodium falciparum isolates. Malar J. 2004;3:21.

35. Staalsoe T, Megnekou R, Fievet N, Ricke CH, Zornig HD, Leke R, Taylor DW, Deloron P, Hviid L. Acquisition and decay of antibodies to pregnancyassociated variant antigens on the surface of Plasmodium falciparuminfected erythrocytes that protect against placental parasitemia. J Infect Dis. 2001;184(5):618-26.

36. Maubert B, Fievet N, Tami G, Cot M, Boudin C, Deloron P. Development of antibodies against chondroitin sulfate A-adherent Plasmodium falciparum in pregnant women. Infect Immun. 1999;67(10):5367-71.

37. Fried M, Nosten F, Brockman A, Brabin BT, Duffy PE. Maternal antibodies block malaria. Nature. 1998;395(6705):851-2.

38. O'Neil-Dunne I, Achur RN, Agbor-Enoh ST, Valiyaveettil M, Naik RS, Ockenhouse CF, Zhou AN, Megnekou R, Leke R, Taylor DW, et al. Graviditydependent production of antibodies that inhibit binding of Plasmodium falciparum-infected erythrocytes to placental chondroitin sulfate proteoglycan during pregnancy. Infect Immun. 2001;69(12):7487-92. 
39. Tuikue Ndam NG, Salanti A, Le-Hesran JY, Cottrell G, Fievet N, Turner L, Sow S, Dangou JM, Theander T, Deloron P. Dynamics of anti-VAR2CSA immunoglobulin $\mathrm{G}$ response in a cohort of senegalese pregnant women. J Infect Dis. 2006;193(5):713-20.

40. Oleinikov AV, Rossnagle E, Francis S, Mutabingwa TK, Fried M, Duffy PE. Effects of sex, parity, and sequence variation on seroreactivity to candidate pregnancy malaria vaccine antigens. J Infect Dis. 2007;196(1): 155-64.

41. Brolin KJM, Persson KEM, Wahlgren M, Rogerson SJ, Chen Q. Differential Recognition of $P$. falciparum VAR2CSA Domains by Naturally Acquired Antibodies in Pregnant Women from a Malaria Endemic Area. PLoS One. 2010;5(2):e9230.

42. Fried M, Kurtis JD, Swihart B, Morrison R, Pond-Tor S, Barry A, Sidibe $Y$, Keita S, Mahamar A, Andemel N, et al. Antibody levels to recombinant VAR2CSA domains vary with Plasmodium falciparum parasitaemia, gestational age, and gravidity, but do not predict pregnancy outcomes. Malar J. 2018:17(1):106.

43. Megnekou R, Staalsoe T, Taylor DW, Leke R, Hviid L. Effects of pregnancy and intensity of Plasmodium falciparum transmission on immunoglobulin $\mathrm{G}$ subclass responses to variant surface antigens. Infect Immun. 2005;73(7):4112-8

44. Stroup DF, Berlin JA, Morton SC, Olkin I, Williamson GD, Rennie D, Moher D, Becker BJ, Sipe TA, Thacker SB. Meta-analysis of observational studies in epidemiology: a proposal for reporting. Meta-analysis of observational studies in epidemiology (MOOSE) group. Jama. 2000;283(15):2008-12.

45. Moher D, Liberati A, Tetzlaff J, Altman DG, Group P. Preferred reporting items for systematic reviews and meta-analyses: the PRISMA statement. PLoS Med. 2009;6(7):e1000097.

46. Sterne JA, Hernan MA, Reeves BC, Savovic J, Berkman ND, Viswanathan M, Henry D, Altman DG, Ansari MT, Boutron I, et al. ROBINS-I: a tool for assessing risk of bias in non-randomised studies of interventions. BMJ. 2016; 355:i4919.

47. Zhang J, Yu KF. What's the relative risk? A method of correcting the odds ratio in cohort studies of common outcomes. JAMA. 1998;280(19):1690-1.

48. DerSimonian R, Laird N. Meta-analysis in clinical trials. Control Clin Trials. 1986;7(3):177-88.

49. Higgins JP, Thompson SG, Deeks JJ, Altman DG. Measuring inconsistency in meta-analyses. BMJ. 2003;327(7414):557-60.

50. loannidis JP. Interpretation of tests of heterogeneity and bias in metaanalysis. J Eval Clin Pract. 2008;14(5):951-7.

51. Aitken EH, Mbewe B, Luntamo M, Maleta K, Kulmala T, Friso MJ, Fowkes FJI, Beeson JG, Ashorn P, Rogerson SJ. Antibodies to chondroitin sulfate Abinding infected erythrocytes: dynamics and protection during pregnancy in women receiving intermittent preventive treatment. J Infect Dis. 2010; 201(9):1316-25

52. Babakhanyan A, Leke RG, Salanti A, Bobbili N, Gwanmesia P, Leke RJ, Quakyi IA, Chen JJ, Taylor DW. The antibody response of pregnant Cameroonian women to VAR2CSA ID1-ID2a, a small recombinant protein containing the CSA-binding site. PLoS One. 2014;9(2):e88173.

53. Beeson JG, Mann EJ, Elliott SR, Lema VM, Tadesse E, Molyneux ME, Brown $\mathrm{GV}$, Rogerson SJ. Antibodies to variant surface antigens of Plasmodium falciparum - infected erythrocytes and adhesion inhibitory antibodies are associated with placental malaria and have overlapping and distinct targets. J Infect Dis. 2004;189(3):540-51.

54. Chandrasiri UP, Randall LM, Saad AA, Bashir AM, Rogerson SJ, Adam I. Low antibody levels to pregnancy-specific malaria antigens and heightened cytokine responses associated with severe malaria in pregnancy. J Infect Dis. 2014;209(9):1408-17.

55. Cox SE, Staalsoe T, Arthur P, Bulmer JN, Hviid L, Yeboah-Antwi K, Kirkwood $B R$, Riley EM. Rapid acquisition of isolate-specific antibodies to chondroitin sulfate A-adherent plasmodium falciparum isolates in Ghanaian primigravidae. Infect Immun. 2005;73(5):2841-7.

56. Duffy PE, Fried M. Antibodies that inhibit Plasmodium falciparum adhesion to chondroitin sulfate a are associated with increased birth weight and the gestational age of newborns. Infect Immun. 2003;71(11):6620-3.

57. Fowkes FJ, McGready R, Cross NJ, Hommel M, Simpson JA, Elliott SR, Richards JS, Lackovic K, Viladpai-Nguen J, Narum D, et al. New insights into acquisition, boosting, and longevity of immunity to malaria in pregnant women. J Infect Dis. 2012;206(10):1612-21.

58. Gnidehou S, Doritchamou J, Arango EM, Cabrera A, Arroyo MI, Kain KC, Ndam NT, Maestre A, Yanow SK. Functional antibodies against VAR2CSA in nonpregnant populations from colombia exposed to Plasmodium falciparum and Plasmodium vivax. Infect Immun. 2014;82(6):2565-73.

59. Guitard J, Cottrell G, Magnouha NM, Salanti A, Li T, Sow S, Deloron P, Ndam NT. Differential evolution of anti-VAR2CSA-lgG3 in primigravidae and multigravidae pregnant women infected by Plasmodium falciparum. Malar J. $2008 ; 7: 10$

60. Lloyd YM, Fang R, Bobbili N, Vanda K, Ngati E, Sanchez-Quintero MJ, Salanti A, Chen JJ, Leke RGF, Taylor DW. Association of Antibodies to VAR2CSA and Merozoite Antigens with Pregnancy Outcomes in Women Living in Yaoundé, Cameroon. Infect Immun. 2018;86(9):e00166-18.

61. Staalsoe T, Shulman CE, Bulmer JN, Kawuondo K, Marsh K, Hviid L. Variant surface antigen-specific lgG and protection against clinical consequences of pregnancy-associated Plasmodium falciparum malaria. Lancet. 2004; 363(9405):283-9.

62. Teo A, Hasang W, Randall LM, Feng G, Bell L, Unger H, Langer C, Beeson JG, Siba PM, Mueller I, et al. Decreasing malaria prevalence and its potential consequences for immunity in pregnant women. J Infect Dis. 2014;210(9): 1444-55.

63. McLean ARD, Stanisic D, McGready R, Chotivanich K, Clapham C, Baiwog F, Pimanpanarak M, Siba P, Mueller I, King CL, et al. P. falciparum infection and maternofetal antibody transfer in malaria-endemic settings of varying transmission. PLoS One. 2017;12(10):e0186577.

64. Ataide R, Mwapasa V, Molyneux ME, Meshnick SR, Rogerson SJ. Antibodies That Induce Phagocytosis of Malaria Infected Erythrocytes: Effect of HIV Infection and Correlation with Clinical Outcomes. PLoS One. 2011;6(7): e22491.

65. Babakhanyan A, Fang R, Wey A, Salanti A, Sama G, Efundem C, Leke RJ, Chen JJ, Leke RG, Taylor DW. Comparison of the specificity of antibodies to VAR2CSA in Cameroonian multigravidae with and without placental malaria: a retrospective case-control study. Malar J. 2015;14(1):480.

66. Chandrasiri UP, Fowkes FJ, Beeson JG, Richards JS, Kamiza S, Maleta K, Ashorn P, Rogerson SJ. Association between malaria immunity and pregnancy outcomes among Malawian pregnant women receiving nutrient supplementation. Malar J. 2016;15(1):547.

67. Feng GQ, Aitken E, Yosaatmadja F, Kalilani L, Meshnick SR, Jaworowski A, Simpson JA, Rogerson SJ. Antibodies to variant surface antigens of Plasmodium falciparum-infected erythrocytes are associated with protection from treatment failure and the development of anemia in pregnancy. $J$ Infect Dis. 2009;200(2):299-306.

68. Hommel M, Elliott SR, Soma V, Kelly G, Fowkes FJI, Chesson JM, Duffy MF, Bockhorst J, Avril M, Mueller I, et al. Evaluation of the antigenic diversity of placenta-binding Plasmodium falciparum variants and the antibody repertoire among pregnant women. Infect Immun. 2010;78(5):1963-78.

69. Mayor A, Rovira-Vallbona E, Machevo S, Bassat Q, Aguilar R, Quinto L, Jimenez A, Sigauque B, Dobano C, Kumar S, et al. Parity and placental infection affect antibody responses against Plasmodium falciparum during pregnancy. Infect Immun. 2011;79(4):1654-9.

70. Mayor A, Kumar U, Bardaji A, Gupta P, Jimenez A, Hamad A, Sigauque B, Singh B, Quinto L, Kumar S, et al. Improved pregnancy outcomes in women exposed to malaria with high antibody levels against Plasmodium falciparum. J Infect Dis. 2013;207(11):1664-74.

71. Serra-Casas E, Menendez C, Bardaji A, Quinto L, Dobano C, Sigauque B, Jimenez A, Mandomando I, Chauhan VS, Chitnis CE, et al. The effect of intermittent preventive treatment during pregnancy on malarial antibodies depends on HIV status and is not associated with poor delivery outcomes. J Infect Dis. 2010;201(1):123-31.

72. Siriwardhana C, Fang R, Salanti A, Leke RGF, Bobbili N, Taylor DW, Chen JJ. Statistical prediction of immunity to placental malaria based on multi-assay antibody data for malarial antigens. Malar J. 2017;16(1):391.

73. Tuikue Ndam N, Denoeud-Ndam L, Doritchamou J, Viwami F, Salanti A, Nielsen MA, Fievet N, Massougbodji A, Luty AJ, Deloron P. Protective antibodies against placental malaria and poor outcomes during pregnancy, Benin. Emerg Infect Dis. 2015;21(5):813-23.

74. Tutterrow YL, Avril M, Singh K, Long CA, Leke RJ, Sama G, Salanti A, Smith JD, Leke RGF, Taylor DW. High levels of antibodies to multiple domains and strains of VAR2CSA correlate with the absence of placental malaria in Cameroonian women living in an area of high Plasmodium falciparum transmission. Infect Immun. 2012;80(4):1479-90.

75. Tutterrow YL, Salanti A, Avril M, Smith JD, Pagano IS, Ako S, Fogako J, Leke RG, Taylor DW. High avidity antibodies to full-length VAR2CSA correlate with absence of placental malaria. PLoS One. 2012;7(6):e40049. 
76. Ataide R, Hasang W, Wilson DW, Beeson JG, Mwapasa V, Molyneux ME, Meshnick SR, Rogerson SJ. Using an Improved Phagocytosis Assay to Evaluate the Effect of HIV on Specific Antibodies to Pregnancy-Associated Malaria. Plos One 2010, 5(5):e10807

77. Khunrae P, Dahllback M, Nielsen MA, Andersen G, Ditlev SB, Resende M, Pinto W, Theander TG, Higgins MK, Salanti A. Full-length recombinant Plasmodium falciparum VAR2CSA binds specifically to CSPG and induces potent parasite adhesion-blocking antibodies. J Mol Biol. 2010;397(3):826-34.

78. Srivastava A, Gangnard S, Dechavanne S, Amirat F, Bentley AL, Bentley GA, Gamain B: Var2CSA Minimal CSA Binding Region Is Located within the NTerminal Region. PLoS One. 2011;6(5):e20270.

79. Doritchamou JY, Herrera R, Aebig JA, Morrison R, Nguyen V, Reiter K, Shimp RL, MacDonald NJ, Narum DL, Fried M, et al. VAR2CSA domain-specific analysis of naturally acquired functional antibodies to Plasmodium falciparum placental malaria. J Infect Dis. 2016;214(4):577-86.

80. Mayor A, Menendez C, Walker PGT. Targeting pregnant women for malaria surveillance. Trends Parasitol. 2019;35(9):677-86.

81. Fried M, Duffy PE. Designing a VAR2CSA-based vaccine to prevent placental malaria. Vaccine. 2015;33(52):7483-8.

82. Tuikue-Ndam N, Deloron P. Developing vaccines to prevent malaria in pregnant women. Expert Opin Biol Ther. 2015;15(8):1173-82.

83. Lopez-Perez M, Larsen MD, Bayarri-Olmos R, Ampomah P, Stevenson L, Arevalo-Herrera M, Herrera S, Hviid L. IgG Responses to the Plasmodium falciparum Antigen VAR2CSA in Colombia Are Restricted to Pregnancy and Are Not Induced by Exposure to Plasmodium vivax. Infect Immun. 2018;86(8): e00136-18.

84. Benavente ED, Oresegun DR, de Sessions PF, Walker EM, Roper C, Dombrowski JG, de Souza RM, Marinho CRF, Sutherland CJ, Hibberd ML, et al. Global genetic diversity of var2csa in Plasmodium falciparum with implications for malaria in pregnancy and vaccine development. Sci Rep. 2018:8(1):15429.

85. Lambert LH, Bullock JL, Cook ST, Miura K, Garboczi DN, Diakite M, Fairhurst RM, Singh K, Long CA. Antigen reversal identifies targets of opsonizing IgGs against pregnancy-associated malaria. Infect Immun. 2014;82(11):4842-53.

86. Ordi J, Ismail MR, Ventura PJ, Kahigwa E, Hirt R, Cardesa A, Alonso PL, Menendez C. Massive chronic intervillositis of the placenta associated with malaria infection. Am J Surg Pathol. 1998:22(8):1006-11.

87. Fried M, Duffy PE. Malaria during Pregnancy. Cold Spring Harb Perspect Med. 2017;7(6):a025551.

88. Fowkes FJ, Richards JS, Simpson JA, Beeson JG. The relationship between anti-merozoite antibodies and incidence of Plasmodium falciparum malaria: a systematic review and meta-analysis. PLoS Med. 2010;7(1):e1000218.

89. Richards JS, Arumugam TU, Reiling L, Healer J, Hodder AN, Fowkes FJ, Cross $\mathrm{N}$, Langer $\mathrm{C}$, Takeo S, Uboldi AD, et al. Identification and prioritization of merozoite antigens as targets of protective human immunity to Plasmodium falciparum malaria for vaccine and biomarker development. Immunol. 2013;191(2):795-809.

\section{Publisher's Note}

Springer Nature remains neutral with regard to jurisdictional claims in published maps and institutional affiliations.

Ready to submit your research? Choose BMC and benefit from:

- fast, convenient online submission

- thorough peer review by experienced researchers in your field

- rapid publication on acceptance

- support for research data, including large and complex data types

- gold Open Access which fosters wider collaboration and increased citations

- maximum visibility for your research: over $100 \mathrm{M}$ website views per year

At $\mathrm{BMC}$, research is always in progress.

Learn more biomedcentral.com/submissions 